\title{
Associations between bone and energy metabolism in cows fed diets differing in level of dietary cation-anion difference and supplemented with cholecalciferol or calcidiol
}

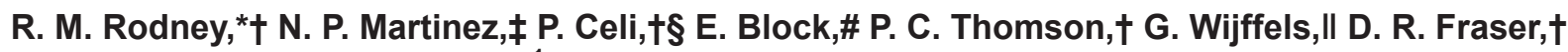 \\ J. E. P. Santos, $\ddagger$ and I. J. Lean* ${ }^{1}$ \\ ${ }^{*}$ Scibus, Camden, New South Wales, Australia 2570 \\ †School of Life and Environmental Sciences, The University of Sydney, Camden, New South Wales, Australia 2570 \\ ‡Department of Animal Sciences, University of Florida, Gainesville 32611 \\ §DSM Nutritional Products, Animal Nutrition and Health, Columbia, MD 21045 \\ \#Arm \& Hammer Animal Nutrition, Princeton, NJ 08543 \\ ॥CSIRO Agriculture, St. Lucia, Queensland, Australia 4067
}

\begin{abstract}
Bone-derived hormones play an important role in metabolism. This study examined the hypothesis that interactions between bone and energy metabolism, particularly those involving osteocalcin, are present in dairy cattle and have feedback mechanisms over time. Associations between metabolites in blood were examined in 32 Holstein cows blocked by parity and milk yield and randomly allocated to diets containing either $0.27 \mathrm{mg} / \mathrm{kg}$ dry matter $(\mathrm{DM})$ calcidiol or cholecalciferol for an anticipated intake of $3 \mathrm{mg} / \mathrm{d}(120,000 \mathrm{IU} / \mathrm{d})$ at $11 \mathrm{~kg}$ of $\mathrm{DM}$, and positive $(+130 \mathrm{mEq} / \mathrm{kg} \mathrm{DM})$ or negative $(-130 \mathrm{mEq} / \mathrm{kg} \mathrm{DM})$ dietary cation-anion difference (DCAD) from 252 d of gestation to calving. Blood was sampled every $3 \mathrm{~d}$, from $9 \mathrm{~d}$ prepartum to $30 \mathrm{~d}$ postpartum, and plasma concentrations of vitamin $\mathrm{D}_{3}$, 25-hydroxyvitamin $\mathrm{D}_{3}$, adiponectin, C-telopeptide of type 1 collagen (CTX1), glucose, insulin-like growth factor 1 (IGF1), insulin, undercarboxylated osteocalcin (uOC), and carboxylated osteocalcin (cOC) were determined. Feeding calcidiol compared with cholecalciferol increased plasma concentrations of 25-hydroxyvita$\min \mathrm{D}_{3}$ pre- $(264.2 \pm 8.0$ vs. $61.3 \pm 8.0 \mathrm{ng} / \mathrm{mL})$ and postpartum $(170.8 \pm 6.2$ vs. $51.3 \pm 6.2 \mathrm{ng} / \mathrm{mL})$ but decreased concentrations of vitamin $\mathrm{D}_{3}$ pre- $(1.2 \pm 0.6$ vs. $14.5 \pm 0.6 \mathrm{ng} / \mathrm{mL})$ and postpartum $(1.9 \pm 0.4$ vs. $3.2 \pm 0.6 \mathrm{ng} / \mathrm{mL}$ ). Prepartum, cows fed the negative DCAD diet had reduced concentrations of vitamin $\mathrm{D}_{3}$ and glucose compared with cows fed a positive DCAD.
\end{abstract}

Received October 23, 2017.

Accepted March 5, 2018.

${ }^{1}$ Corresponding author: ianl@scibus.com.au
The combination of negative DCAD and cholecalciferol reduced IGF1 concentrations prepartum. The DCAD treatment had no effect on postpartum concentrations of metabolites. Nulliparous cows had increased concentrations of OC, CTX1, IGF1, glucose, and insulin compared with parous cows. Time series analysis identified associations between metabolites on the same day and over 3 -d lags up to \pm 9 d that suggest feedback between 25-hydroxyvitamin $\mathrm{D}_{3}$ and vitamin $\mathrm{D}_{3}$ in the negative lags, indicating that 25-hydroxyvitamin $\mathrm{D}_{3}$ may exert feedback on vitamin $\mathrm{D}_{3}$ but not vice versa. We found evidence of a feedback mechanism between vitamin $\mathrm{D}_{3}$ and IGF1, with positive effect size (ES) on the same day and $3 \mathrm{~d}$ later, and negative ES $9 \mathrm{~d}$ later, that was more evident in cholecalciferol-fed cows. This suggests an important role of IGF1 in integrating bone metabolism with energy and protein metabolic pathways. Evidence of feedback was found between uOC and particularly cOC with IGF1, with positive ES on the same day but negative ES $6 \mathrm{~d}$ before and $6 \mathrm{~d}$ after. An association between $\mathrm{uOC}$ or $\mathrm{cOC}$ and IGF1 has not been previously identified in cattle and suggests that both $\mathrm{uOC}$ and cOC may have marked biological activity. Associations between $\mathrm{OC}$ and insulin identified in mice were not observed herein, although associations between OC and glucose were similar to those between IGF1 and glucose, supporting associations between glucose, OC, and IGF1. We provide further statistical evidence of crosstalk between vitamin D compounds, bone hormones, and energy metabolism in cattle. In particular, associations between $\mathrm{uOC}$ or $\mathrm{cOC}$ and IGF1 may provide links between prepartum diets and observations of prolonged increases in milk production and allow better control of peripartum metabolism.

Key words: dietary cation-anion difference, IGF1, osteocalcin, vitamin D 


\section{INTRODUCTION}

The interplay between bone and energy metabolism has been identified in murine models (Lee et al., 2007), and associations between bone markers and energy metabolism have been demonstrated in humans (Wolf, 2008). We have postulated a specific role for bone metabolism, and links to energy metabolism, in the adaptation of dairy cows to lactation (Lean et al., 2014) and anticipated that these associations are influenced by prepartum dietary interventions. Such interventions have had profound and long-lasting effects on productivity, health, and fertility of cows (Lean et al., 2014; Martinez et al., 2018b).

Lee et al. (2007) identified actions of the osteoblastderived hormone osteocalcin (OC) that created a feedback loop between bone and energy metabolism. Osteocalcin is produced by mature osteoblasts and undergoes vitamin $\mathrm{K}$-dependent $\gamma$-carboxylation, resulting in carboxylated $\mathrm{OC}(\mathbf{c O C})$ that increases the affinity of the molecule for $\mathrm{Ca}$ and hydroxyapatite in bones and plays a role in bone accretion in numerous species, including bovine (Van Mosel and Corlett, 1990). A smaller fraction of $\mathrm{OC}$ remains undercarboxylated $(\mathbf{u O C})$ and interacts with the G-protein coupled receptor GPRC6A in numerous tissues (Wei and Karsenty, 2015). In a influential paper, Lee et al. (2007) conducted a series of experiments that demonstrated that OC promoted pancreatic $\beta$-cell proliferation and insulin secretion, independently increased peripheral tissue insulin sensitivity, and stimulated adiponectin secretion by adipocytes. On the other hand, adiponectin has been shown to increase osteoblast proliferation and differentiation (Berner et al., 2004), bone deposition (Kanazawa et al., 2007), and glucose uptake by skeletal muscle, and it may suppress hepatic gluconeogenesis (Yamauchi et al., 2002). Insulin acts to directly inhibit osteoblast activity, thereby enhancing bone resorption (Lee et al., 2007). Associations have been made between obesity and $\mathrm{Ca}$ metabolism in cattle (Heuer et al., 1999; DeGaris et al., 2010) and induced subclinical hypocalcemia resulted in transient insulin resistance based on increased blood glucose and reduced plasma insulin concentrations in dairy cattle (Martinez et al., 2014).

Diets with negative DCAD enhance the response to parathyroid hormone in dairy cows, which increases concentrations of 1,25-dihydroxyvitamin $\mathrm{D}_{3}$ and $\mathrm{Ca}$ in blood of cows (Goff et al., 2014). The increased concentrations of 1,25-dihydroxyvitamin $\mathrm{D}_{3}$ in cows fed acidogenic diets are presumed to be caused by increased renal synthesis of the vitamin (Goff et al., 1991, 2014). Furthermore, acidogenic diets increase blood concentrations of total and ionized $\mathrm{Ca}$ on the day of calving and in the following days (Oetzel et al., 1991; Phillippo et al., 1994; Rodney et al., 2018), likely because of increased concentrations of 1,25-dihydroxyvitamin $\mathrm{D}_{3}$ and increased responsiveness of target tissues to the vitamin (Goff and Horst, 1997). Vitamin $\mathrm{D}$ plays a crucial role in the absorption of minerals from the gastrointestinal tract including the forestomachs (Sidler-Lauff et al., 2010), and it is essential for bone metabolism, regulating the activity of osteoblasts and osteoclasts (Tanaka and DeLuca, 1971). Complementary to vitamin D, acidogenic diets enhance Ca flux from the mucosal to the serosal side of the gastrointestinal tract of ruminants (Wilkens et al., 2016) and have been shown to improve $\mathrm{Ca}$ and $\mathrm{Mg}$ retention in dairy cows (Abu Damir et al., 1994). Vitamin D responsive elements have been identified in the OC gene BGLAP (Terpening et al., 1991), and 1,25-dihydroxyvitamin $\mathrm{D}_{3}$ and other vitamin $\mathrm{D}$ metabolites can activate the gene and stimulate OC synthesis (Uchida et al., 1994). Dietary interventions that influence mineral and vitamin D metabolism might also influence energy metabolism in dairy cows as part of the homeorhetic adaptations to lactation (Bauman and Currie, 1980).

Establishing associations with potential feedback loops among mineral-bone-energy metabolism in transition dairy cows can create a novel hypothesis on the mechanisms by which nutrients and dietary interventions influence adaptations to lactation. This cross-talk and integration of metabolism has been elegantly demonstrated in murine models (Lee et al., 2007), and may apply to humans (Wolf, 2008) and possibly dairy cattle (Lean et al., 2014). We hypothesized that associations between bone-derived compounds and those involved in energy metabolism would be evident. The objectives were to use time series analysis to identify associations over time between plasma compounds involved in bone, mineral, and energy metabolism in transition dairy cows fed diets differing in level of DCAD and source of supplemental vitamin D.

\section{MATERIALS AND METHODS}

Throughout the manuscript, sources of vitamin D fed to cows prepartum will be referred as cholecalciferol (CH) and calcidiol (CA), whereas vitamin D metabolites measured in plasma will be referred to as vitamin $\mathrm{D}_{3}$ and 25-hydroxyvitamin $\mathrm{D}_{3}$.

\section{Cows, Diets, and Treatments}

All procedures were approved by the University of Florida Institutional Animal Care and Use Committee (protocol number 201408331). This study is part of a series of experiments conducted to evaluate the effects of level of dietary DCAD and source of supplemental 
vitamin D fed prepartum on transition cow metabolism, production, and health (Martinez et al., 2018a,b; Rodney et al., 2018). Details of the diets used are provided in Supplemental Table S1 (https://doi.org/10.3168/jds .2017-14033).

Pregnant Holstein cows, 20 parous and 12 nulliparous, were moved into the experimental pens at approximately $252 \mathrm{~d}$ of gestation to become acclimated to the facilities and be trained in the use of the Calan Broadbent feeding system (American Calan Inc., Northwood, NH). For consistency of terminology, cows are referred to herein as either nulliparous (those that were nulliparous prepartum and primiparous postpartum) or parous (those that had previously calved). Cows were blocked by parity ( 0 vs. $>0$ ) and, for parous cows, 305-d milk yield during the previous lactation. Within each block, cows were randomly assigned into 1 of 4 dietary treatments in a randomized complete block design. Measurements started at $255 \mathrm{~d}$ of gestation until $49 \mathrm{~d}$ postpartum.

Treatments were arranged in a $2 \times 2$ factorial, with 2 levels of DCAD [DCAD, $\mathrm{mEq} / \mathrm{kg}=\left(\mathrm{Na}^{+}+\mathrm{K}^{+}\right)-$ $\left.\left(\mathrm{Cl}^{-}+\mathrm{S}^{-}\right)\right]$: positive $(+130 \mathrm{mEq} / \mathrm{kg})$ or negative $(-130$ $\mathrm{mEq} / \mathrm{kg}$ ), achieved by replacing soybean meal with a high-protein acidogenic product (Bio-Chlor, Church \& Dwight Co. Inc., Trenton, NJ), and 2 forms of vitamin D: cholecalciferol $\left(\mathbf{C H}\right.$; Rovimix $\mathrm{D}_{3}$; a product containing $300 \mathrm{mg}$ of cholecalciferol per kg; Division of Animal Nutrition and Health, DSM Nutritional Products LLC, Parsippany, NJ) or calcidiol (CA; Hy-D; a product containing $153 \mathrm{mg}$ of calcidiol per kg; Division of Animal Nutrition and Health, DSM Nutritional Products, LLC), both fed at $0.27 \mathrm{mg}$ of vitamin D per $\mathrm{kg}$ of diet DM. Hence, the 4 treatments were positive DCAD and $\mathrm{CH}(\mathbf{P C H})$, positive DCAD and CA (PCA), negative DCAD and $\mathrm{CH}(\mathbf{N C H})$, and negative DCAD and $\mathrm{CA}$ (NCA). The 32 cows encompassed 8 blocks of 4 cows each that represented all 4 treatments within a block. The diets were isocaloric and isonitrogenous and had similar mineral content, except for $\mathrm{Cl}$ and $\mathrm{S}$, which varied to achieve the desired DCAD, and the 2 sources of supplemental vitamin D.

Cows were individually fed diets as TMR using a Calan Broadbent feeding system. All cows had similar exposure to sunlight, as the housing facilities were open to ambient light. Prepartum, treatments were applied to diets and offered once daily until calving. After calving, a common lactation diet was fed to all cows postpartum. Amounts offered and refused were measured for individual cows daily, and feed allowances were calculated daily with the goal of $5 \%$ refusals. Full details of experimental procedures, cow housing, sample collection, diet composition, and analysis of feeds can be found in Martinez et al., (2018a).

\section{Blood Sample Collection and Analysis}

Blood was sampled from the coccygeal vessels 3 times weekly prepartum and every $3 \mathrm{~d}$ from the day of parturition until 30 DIM and was taken approximately $3 \mathrm{~h}$ after the morning feeding. Only the samples on or closest to $\mathrm{d}-9,-6$, and -3 relative to calving and those taken on the day of and every $3 \mathrm{~d}$ from calving to 30 DIM were used for analyses. Plasma concentrations of vitamin $\mathrm{D}_{3}, 25$-hydroxyvitamin $\mathrm{D}_{3}, \mathrm{uOC}, \mathrm{cOC}$, C-telopeptide of type 1 collagen (CTX1), glucose, insulin, IGF1, and adiponectin were analyzed according to the procedures outlined in Rodney et al. (2018) and Martinez et al. (2018a). Briefly, concentrations of vitamin $\mathrm{D}_{3}$ and 25-hydroxyvitamin $\mathrm{D}_{3}$ were analyzed by HPLC coupled with MS detection by the Analytical Research Center of DSM Nutritional Products (Kaiseraugst, Switzerland). Personnel running the assays were blind to treatments. The lower limits of quantification for the assays were $0.5 \mathrm{ng} / \mathrm{mL}$ for vitamin $\mathrm{D}_{3}$ and 1.0 $\mathrm{ng} / \mathrm{mL}$ for 25 -hydroxyvitamin $\mathrm{D}_{3}$. Concentrations of $\mathrm{uOC}$ and cOC were analyzed by ELISA (catalog nos. MK111 and MK118; Clontech Labs, Takara Bio Inc., Mountain View, CA). The intra- and interassay coefficients of variation $(\mathbf{C V})$ were, respectively, 5.2 and $8.3 \%$ for $\mathrm{uOC}$, and 3.7 and $1.4 \%$ for cOC. C-Terminal telopeptide of type 1 collagen was analyzed by ELISA (catalog no. AC-02F1; IDS, The Boldons, UK), and the intra- and interassay CV were, respectively, 2.2 and $7.7 \%$. Concentrations of glucose in plasma were determined by colorimetric continuous flow analysis (Autoanalyzer II, Seal Analytical, Southampton, UK) using a modification of the method described by Gochman and Schmitz (1972). Intra- and interassay CV were 2.6 and $3.8 \%$, respectively. Concentrations of insulin (Mercodia Bovine Insulin ELISA, Mercodia Inc., Uppsala, Sweden) and IGF-1 in plasma (R\&D Systems Inc., Minneapolis, MN) were analyzed by enzyme immunoassays. The intra- and interassay CV were, respectively, 3.1 and $4.7 \%$ for insulin, and 6.0 and $10.3 \%$ for IGF-1. Concentrations of adiponectin were analyzed by ELISA at CSIRO Agriculture (St Lucia, QLD, Australia). The intra- and interassay CV were, respectively, 11.9 and $10.2 \%$.

Daily measurement of DMI was evaluated prepartum and for the first 42 DIM, whereas daily milk yield and BW and weekly BCS were collected for the first 49 DIM. Details are presented elsewhere (Martinez et al., 2018a).

\section{Statistical Analysis}

The cows in this study are a subset of those examined in Martinez et al. (2018a,b) and Rodney et al. (2018). 
Eight blocks of cows each containing a cow assigned to 1 of the 4 treatments ( $\mathrm{n}=4$ cows/block), with 3 blocks of nulliparous and 5 blocks of parous cows, were selected for inclusion in the study based on completeness of samples taken over the study period.

Cow performance and concentrations of metabolites in plasma were analyzed by ANOVA with mixed models using the MIXED procedure of SAS (version 9.4, SAS Institute Inc., Cary, NC). Normality of residuals and homogeneity of variance were examined for each continuous variable analyzed after fitting the statistical model. Responses that violated the assumptions of normality were subjected to power transformation according to the Box-Cox procedure (Box and Cox, 1964) using PROC TRANSREG in SAS. For transformed data, the least squares means and standard errors of the means were back transformed for presentation according to Jørgensen and Pedersen (1998). Concentrations of CTX1 and insulin had to be log-transformed before analyses either because of heteroscedasticity or because residuals were not normally distributed.

Pre- and postpartum data were analyzed separately. The statistical models included the fixed effects of level of DCAD (positive vs. negative) and source of vitamin $\mathrm{D}$ (CH vs. CA), and all 2-, 3-, and 4-way interactions between and among DCAD, source of vitamin D, parity, and time were included. Random effects included block and cow nested within DCAD and vitamin D. The repeated statement was included in all mixed models and day was the specified repeated effect. The covariance structure was modeled based on spacing between measurements and selection was based on model fit with the smallest corrected Akaike's information criterion and autoregressive 1 was selected. The Kenward-Roger method was used to compute the approximate denominator degrees of freedom for the $F$ tests in the statistical models. When an interaction was significant, pairwise comparisons were performed with the adjustment by the method of Tukey. Statistical significance was considered at $P \leq 0.05$, and tendency was considered at $0.05<P \leq 0.10$.

A time series analysis was conducted using Stata (Intercooled Stata version 13; StataCorp LLC, College Station, TX) to examine relationships between metabolites over time. The data from each cow and metabolite from $9 \mathrm{~d}$ before calving to $30 \mathrm{~d}$ after calving ( $\mathrm{n}=14$ samples/cow) were detrended separately to produce an approximately stationary series (Shumway, 1988). Spline trends were removed from each series using Stata UVRS procedure and the data points produced effectively equate to residuals from these models. Cross-correlations were then performed using the XCORR procedure of Stata on these data for pairs of metabolites $(x$ and $y)$ and for each lag $(m)$ using the following model:

$$
\rho_{x y}^{T}(m)=\frac{R_{x y}^{T}(m)}{\sqrt{R_{x}^{T}(0) R_{y}^{T}(0)}},
$$

for the cross-correlation $\rho$ of $x y$ at lag $m$, where it is assumed that series $x$ and $y$ are stationary, $R^{T}{ }_{x}(0)$ and $R_{y}^{T}(0)$ are the mean sample auto-covariances for series $x$ and $y$ observed at time points $t=0,1, \ldots, T-1$, and the cross-covariance function for $x y$ at lag $m$ is

$$
R_{x y}^{T}(m)=T^{-1} \sum_{t=0}^{T-1-m}\left(x_{t+m}-x^{T}\right)\left(y_{t}-y^{T}\right), m \geq 0
$$

and

$$
R_{x y}^{T}(-m)=R_{y x}^{T}(m)
$$

for negative lags (Shumway, 1988). Cross-correlation coefficients were transformed using Fisher's transformation. Finally, a random effect, pooled effect of estimate, was produced using DerSimonian and Laird random effects meta-analytic methods (DerSimonian and Laird, 1986) with the METAN procedure of Stata, in which the transformed cross-correlations for each cow were treated as a separate study as described by Hedges and Vevea (1998). The effect size (ES) of each observation is then given weight $(\omega)$ :

$$
\omega_{i}=1 /\left[\operatorname{se}\left(\hat{\theta}_{i}\right)^{2}+\hat{\tau}^{2}\right],
$$

where $\left(\theta_{i}\right)$ is the effect size for an individual comparison, $\hat{\tau}^{2}$ is the variance, se is the standard error, and the pooled ES is given by the following, where DL = DerSimonian and Laird:

$$
\hat{\theta}_{\mathrm{DL}}=\left(\sum \omega_{i} \hat{\theta}_{i}\right) /\left(\sum \omega_{i}\right) .
$$

The standard error of that estimate is

$$
\operatorname{se}\left\{\hat{\theta}_{\mathrm{DL}}\right\}=1 / \sqrt{\sum \omega_{i}}
$$

(Palmer and Sterne, 2009). Effect sizes were not transformed back to correlations. Significant effects of vitamin D or DCAD treatments, or their interactions, were identified for each pair of metabolites at each lag using ANOVA using the ANOVA procedure in Stata. 


\section{Interpretation of Time Series Results}

Briefly, when the relationship between 2 metabolites, for a given treatment, was significantly different from zero, as determined by the $95 \%$ CI, it is highlighted in Tables 4 and 5 by use of italic and bold fonts. Values in italic font indicate a positive ES between the 2 metabolites, whereas values in bold indicate a negative ES between the 2 metabolites. The relationship between each pair of metabolites was assessed as follows. The ES at lag zero reflects the pooled ES for the group of cows of the correlations between the 2 metabolites measured on the same day. The negative lags (i.e., -3 , -6 , and -9 ) present the pooled ES of the cows for the cross correlations for the first metabolite with the second metabolite 3 to 9 d later. For example, in Table 4, the ES for lag -9 between 25-hydroxyvitamin $\mathrm{D}_{3}$ (the first metabolite) and vitamin $\mathrm{D}_{3}$ concentrations (the second metabolite) $9 \mathrm{~d}$ later is -0.380 in the $\mathrm{PCH}$ group. Similarly, a positive lag $(+3,+6$, and +9$)$ shows the pooled ES for the cows of the cross-correlations between the first metabolite with the second metabolite 3 to 9 d before. For example, in Table 5, 25-hydroxyvitamin D3 (the first metabolite) and CTX1 (the second metabolite) at $\operatorname{lag}+6$ (i.e., $6 \mathrm{~d}$ earlier) is 0.246 for cows fed PCH. The ES is also termed the "standardized mean difference" and, as such, essentially represents a Z-distribution response. Consequently, an ES of 1 represents a difference of $1 \mathrm{SD}$ in response for the 2 metabolites. Cohen (1988) defined ES as small $(\mathrm{ES}=$ $0.2)$, medium $(\mathrm{ES}=0.5)$, or large $(\mathrm{ES} \geq 0.8)$. Results are presented in tables and changes over time are illustrated in figures.

In Tables 4 and 5, superscripts indicate instances in which, across all 4 treatments, an effect $(P<0.05)$ of treatment influenced the ES between the pair of metabolites. Superscript "a" indicates an influence of vitamin D treatment, superscript "b" indicates an influence of DCAD treatment, and superscript "c" indicates that the interaction of the vitamin D and DCAD treatments affected the ES.

\section{RESULTS AND DISCUSSION}

The intent of the study was to identify interactions between bone and energy metabolism in dairy cows during the transition period, and to determine whether these associations are influenced by dietary vitamin D and DCAD interventions before calving. As these cows are a sub-population of those described in Martinez et al. (2018a,b) and Rodney et al. (2018), the results pertaining to the responses given in Tables 1, 2, and 3 are consistent with those of Martinez et al. (2018a,b) but more conservative because of the smaller sample

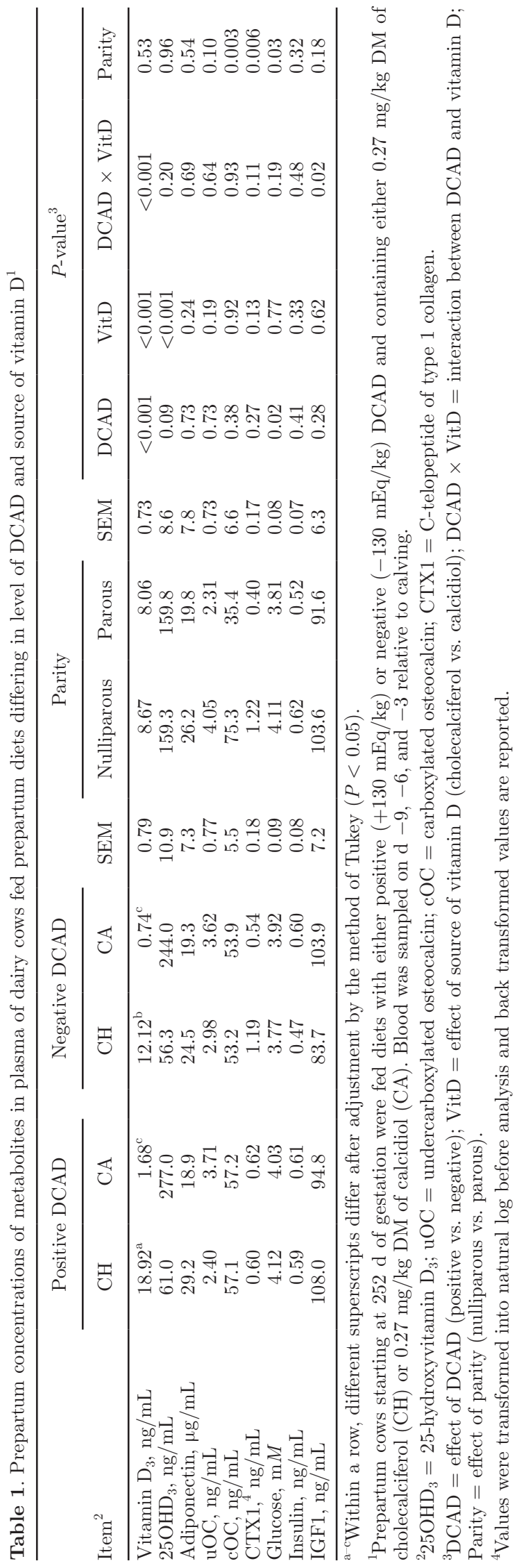

Journal of Dairy Science Vol. 101 No. 7, 2018 

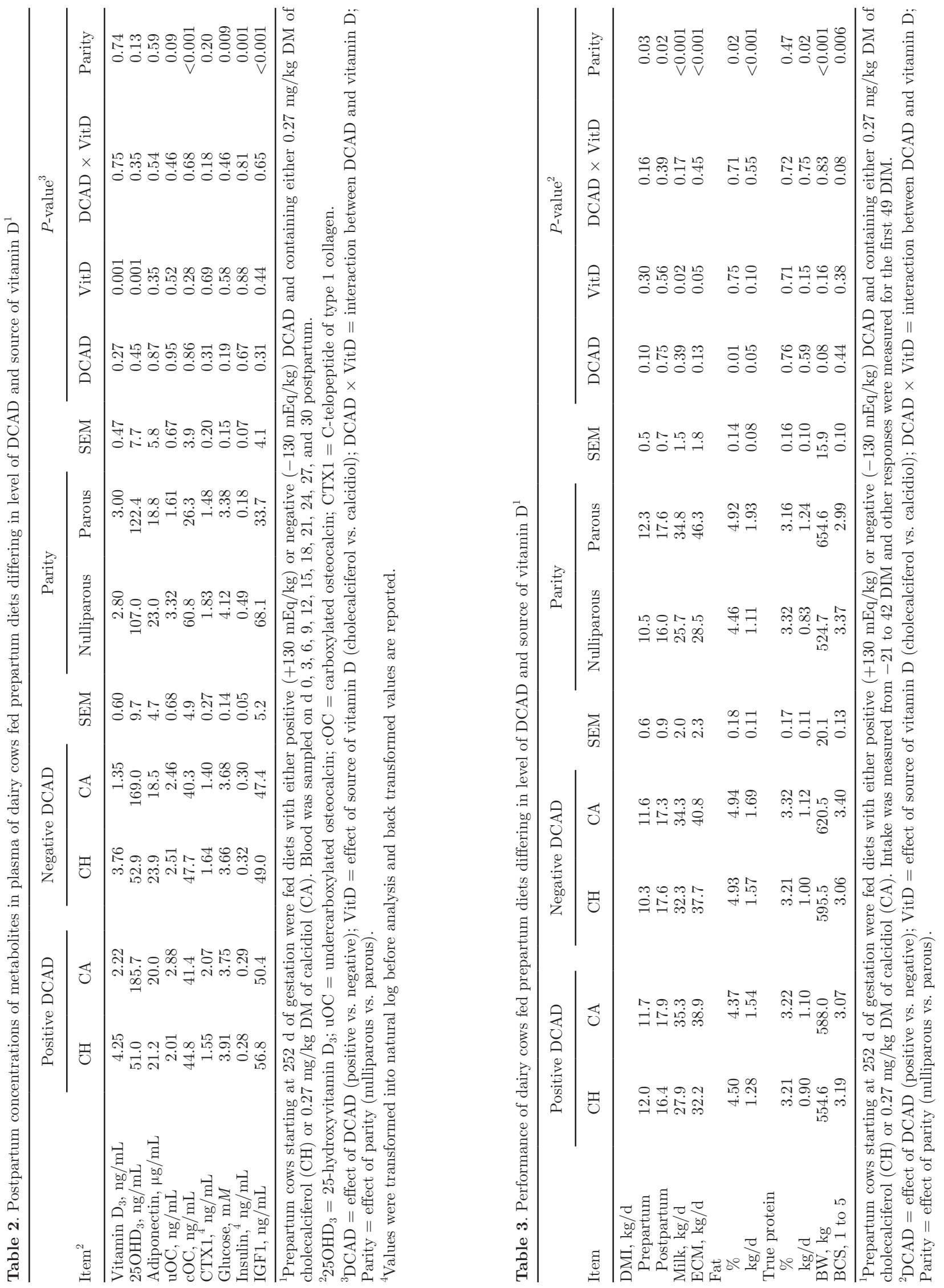
size than the original experiment. There is a proposed hierarchy of effects in this study, with a presumption that the form of vitamin D supplemented and DCAD would influence responses: first, those directly associated with the treatments imposed and, subsequently, those related to metabolites influenced by the treatments.

\section{Pre- and Postpartum Concentrations of Metabolites}

Supplementing CA increased $(P<0.001)$ plasma concentrations of 25 -hydroxyvitamin $\mathrm{D}_{3}$ (61.3 vs. 264.2 $\pm 8.0 \mathrm{ng} / \mathrm{mL})$ and reduced $(P<0.001)$ concentrations of vitamin $\mathrm{D}_{3}(14.55$ vs. $1.56 \pm 0.56 \mathrm{ng} / \mathrm{mL})$ prepartum compared with $\mathrm{CH}$ (Table 1, Figure 1A and 1B), findings consistent with previous studies (Taylor et al., 2008; Wilkens et al., 2012; Weiss et al., 2015). The concentrations exceed those typically observed when cows are fed amounts of vitamin $\mathrm{D}_{3}$ according to current guidelines (50 to $80 \mathrm{ng} / \mathrm{mL} 25$-hydroxyvitamin $\mathrm{D}_{3}$; Horst et al., 1994). The interaction $(P<0.001)$ between DCAD and vitamin $\mathrm{D}$ for plasma concentrations of vitamin $\mathrm{D}_{3}$ prepartum indicates that differences were greater when cows were fed the diet with positive DCAD than the
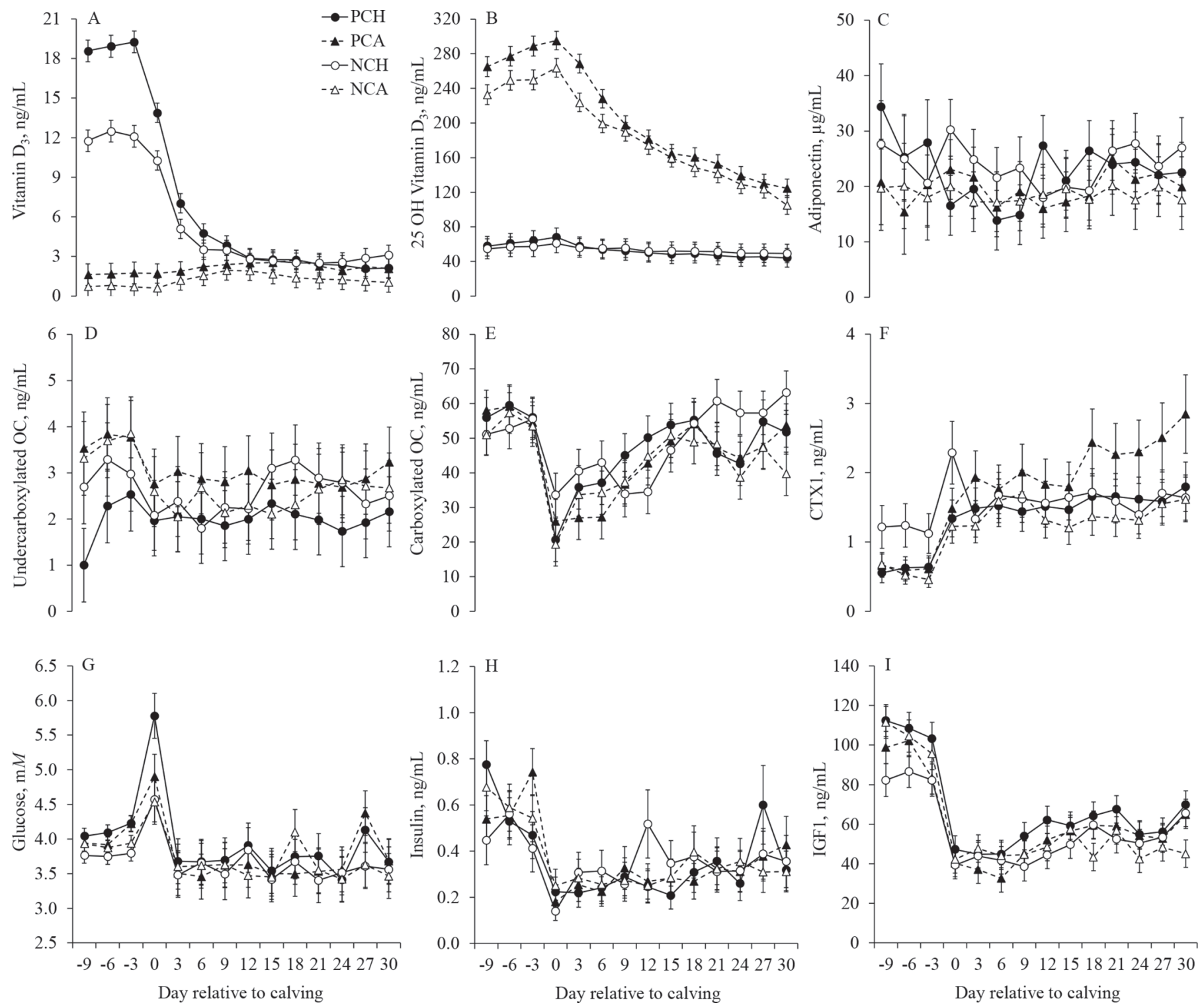

Figure 1. Plasma concentrations of vitamin $\mathrm{D}_{3}(\mathrm{~A})$, 25-hydroxyvitamin $\mathrm{D}_{3}(\mathrm{~B})$, adiponectin (C), undercarboxylated osteocalcin (OC; D), carboxylated OC (E), C-telopeptide of type 1 collagen (CTX1; F), glucose (G), insulin (H), and IGF1 (I) in plasma of cows from d -9 to 30 relative to calving. Prepartum cows starting at $252 \mathrm{~d}$ of gestation were fed diets with either positive $(\mathrm{P} ;+130 \mathrm{mEq} / \mathrm{kg})$ or negative $(\mathrm{N} ;-130 \mathrm{mEq} /$ $\mathrm{kg}$ ) DCAD and containing either $0.27 \mathrm{mg} / \mathrm{kg}$ DM of cholecalciferol $(\mathrm{CH})$ or $0.27 \mathrm{mg} / \mathrm{kg}$ DM of calcidiol (CA). Error bars represent the SEM. 


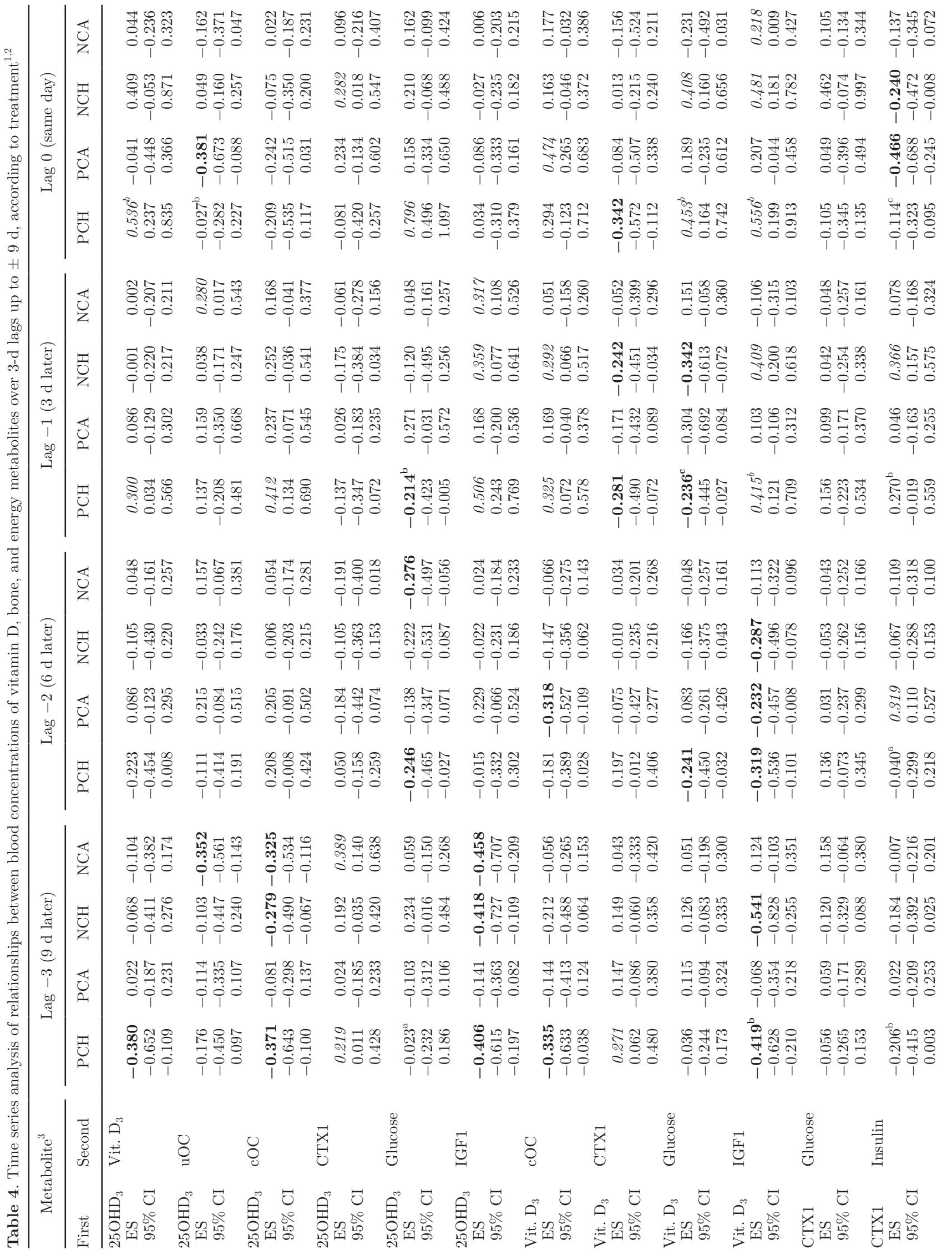


BONE AND ENERGY METABOLISM

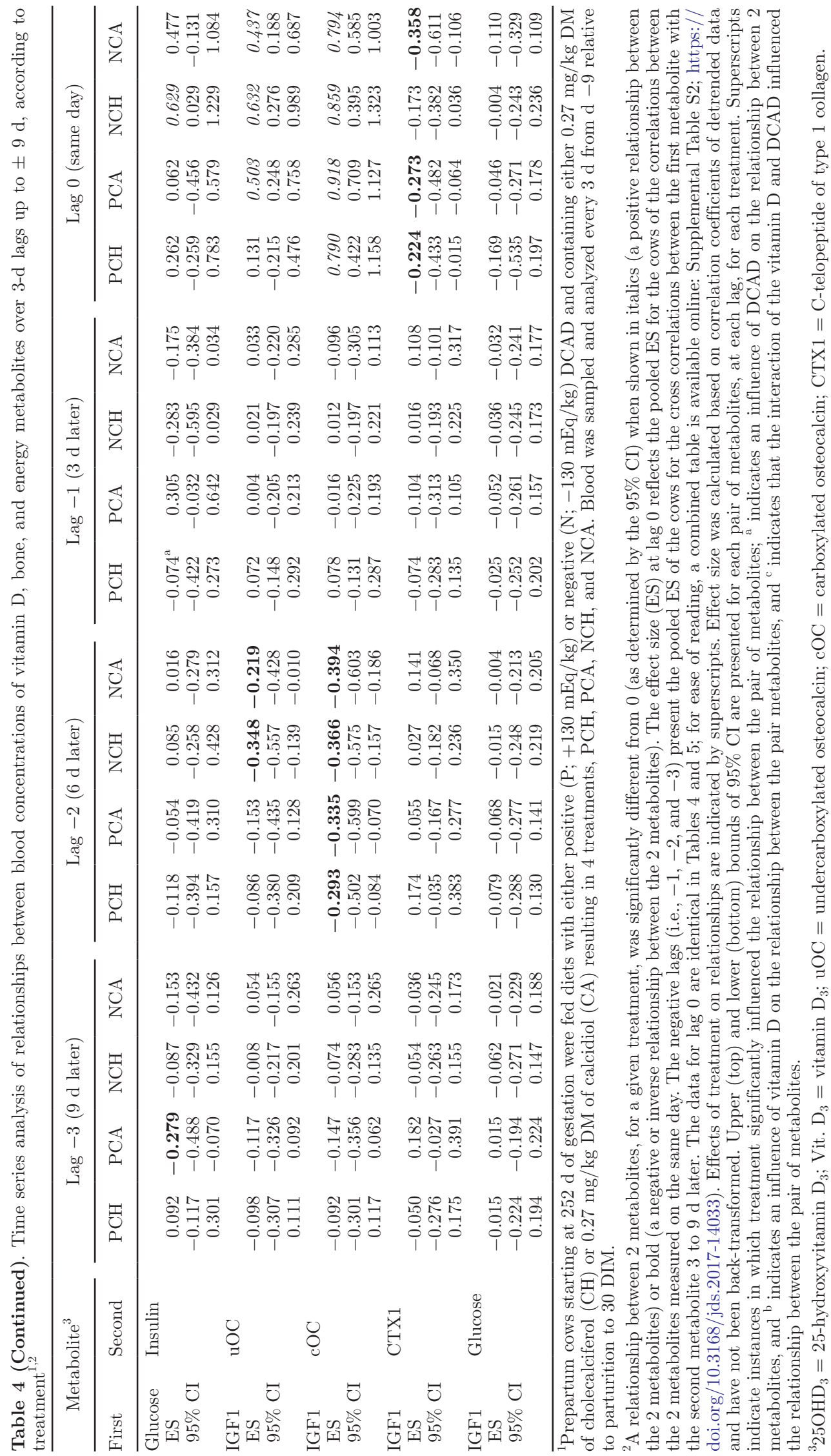




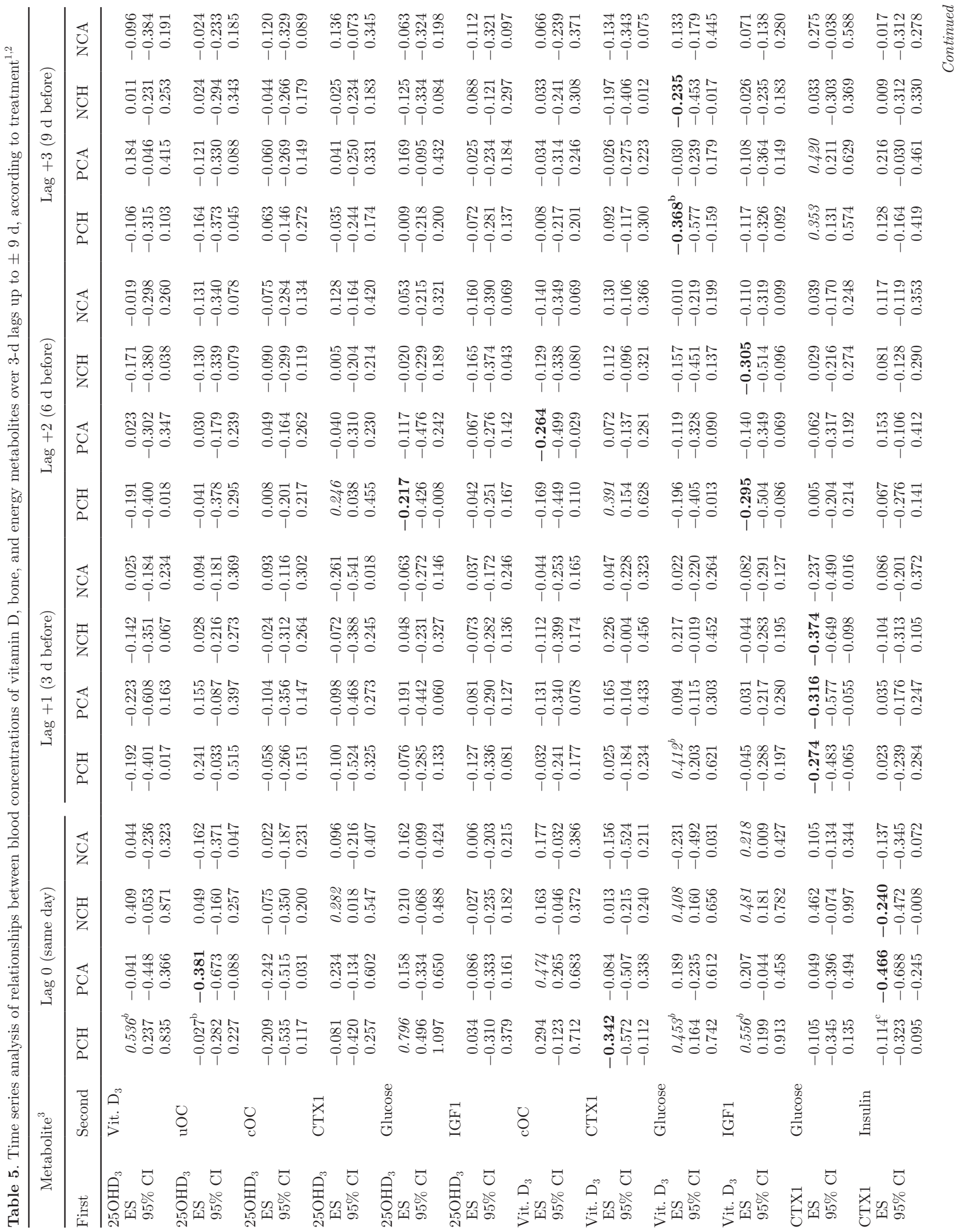




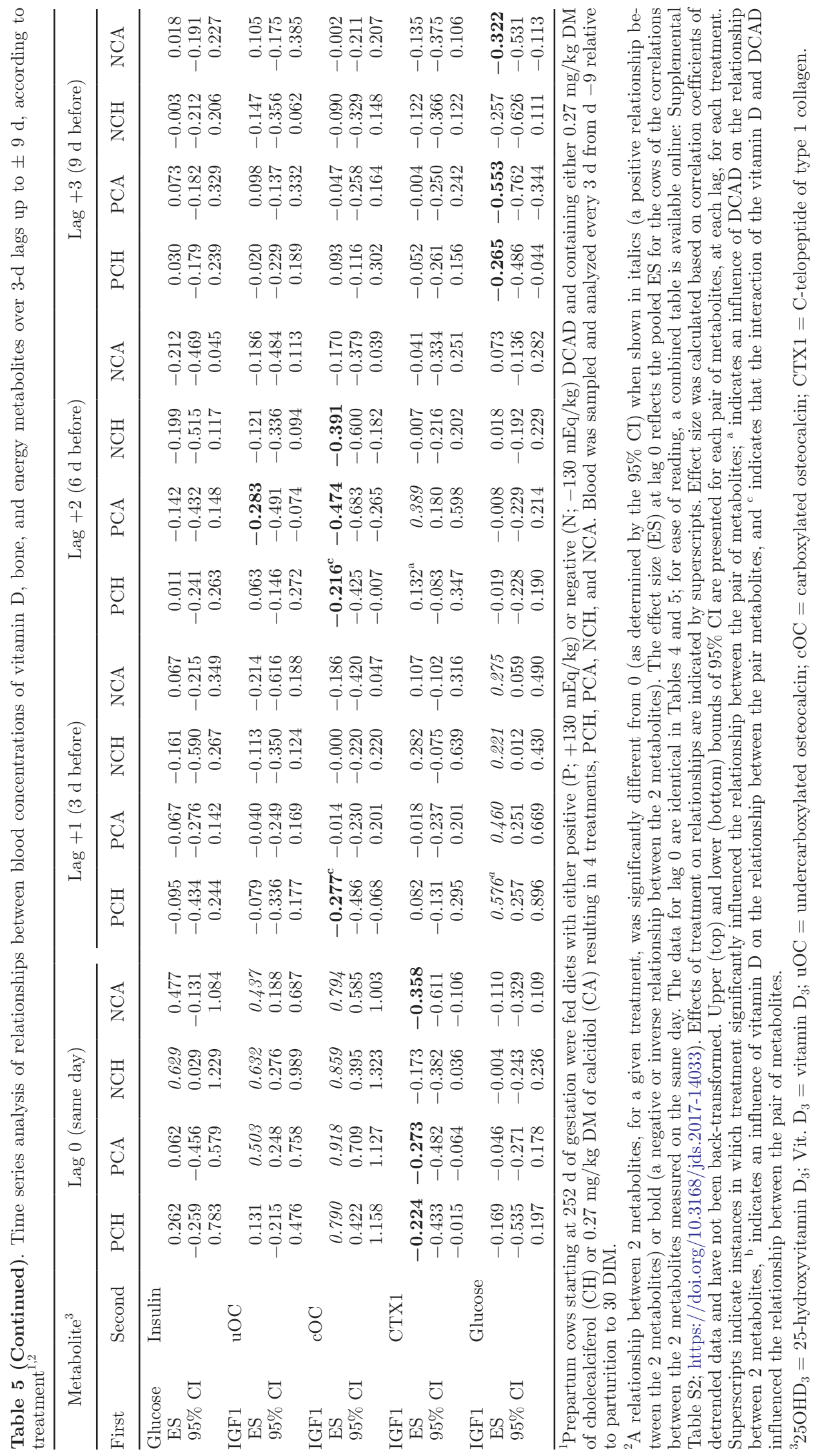


diet with negative DCAD. Concentrations of vitamin $\mathrm{D}_{3}$ postpartum were greater $(P=0.001)$ for cows fed $\mathrm{CH}$ than CA (Table 2), although they rapidly declined $(P$ $<0.001$ ) postpartum to reach those of cows fed CA by 12 DIM (Figure 1A). Concentrations of 25-hydroxyvitamin $\mathrm{D}_{3}$ remained greater for cows fed $\mathrm{CA}$ than $\mathrm{CH}$ postpartum $(\mathrm{CH}=52.0$ vs. $\mathrm{CA}=177.4 \pm 6.9 \mathrm{ng} / \mathrm{mL})$, but these declined at a greater rate $(P<0.001)$ after calving in cows fed CA than $\mathrm{CH}$ (Figure 1B). We found no effect of DCAD or interactions between DCAD and vitamin $\mathrm{D}$ treatments on postpartum concentrations of vitamin $\mathrm{D}$ metabolites. The greater vitamin $\mathrm{D}_{3}$ concentrations in cows fed the positive DCAD diet reflected, in part, an increased DMI and hence supplement intake; however, the effect appeared to be larger than the increase in DMI would explain. Thus, it is possible that changes in acid-base status influence absorption or postabsorptive metabolism of vitamin $\mathrm{D}$ compounds provided in the diet, particularly by increasing 1,25-dihydroxyvitamin $\mathrm{D}_{3}$ production and consequently reducing 25-hydroxyvitamin $\mathrm{D}_{3}$ concentrations.

Cows produce vitamin $\mathrm{D}_{3}$ in the skin in response to UV exposure, as was recently shown in cows not supplemented with cholecalciferol for 6 mo and exposed to UV light for 30, 90, or $120 \mathrm{~min} / \mathrm{d}$ for $28 \mathrm{~d}$ (Hymøller et al., 2017). Exposure to UV light increased plasma concentrations of 25-hydroxyvitamin $\mathrm{D}_{3}$ linearly from approximately $5 \mathrm{ng} / \mathrm{mL}$ on experiment d 0 to almost 40 $\mathrm{ng} / \mathrm{mL}$ on d 28 in cows receiving either 90 or $120 \mathrm{~min} / \mathrm{d}$ of light exposure (Hymøller et al., 2017). Therefore, some background concentration of vitamin D metabolites was expected in cows from endogenous synthesis or from previous supplementation before initiation of the experiment. Nevertheless, exposure of cows to sunlight was similar in all treatments in the present experiment as they were housed in the same pen. The vitamin D produced in skin is predominantly bound to vitamin $\mathrm{D}$ binding protein, and some to albumin, for transport in the blood (Bikle et al., 1986). However, oral sources of vitamin D are taken up with chylomicron lipid (Haddad et al., 1993). These different presentations of vitamin D affect metabolism, as vitamin D or 25-hydroxyvitamin $\mathrm{D}_{3}$ bound to lipid may be removed by the liver and therefore be less available than vitamin $\mathrm{D}$ derived from skin or injected intramuscularly.

Concentrations of adiponectin, $\mathrm{uOC}, \mathrm{cOC}$, and CTX1 in plasma pre- and postpartum did not differ with treatment (Tables 1 and 2). Concentrations of adiponectin and $\mathrm{uOC}$ remained relatively stable throughout the transition period (Figure 1C and 1D), whereas those of cOC underwent dynamic changes during the transition period with an abrupt decline on the day of calving followed by a steady increase $(P<0.001)$ in the first 30 DIM in all 4 treatments (Figure 1E). Concentrations of CTX1 remained constant prepartum, and then increased immediately after calving and plateaued by 3 DIM (Figure 1F). Nulliparous cows had greater concentrations of $\mathrm{cOC}(P<0.01)$, and tended to have greater concentrations of uOC $(P \leq 0.10)$ than parous cows pre- and postpartum. Concentrations of CTX1 prepartum, but not postpartum, were greater ( $P$ $=0.006)$ in nulliparous than parous cows.

Level of DCAD altered $(P=0.02)$ prepartum concentration of glucose in plasma (positive $=4.07$ vs. negative $=3.84 \mathrm{~m} M$; Table 1 ) but not postpartum (Table 2 ). Source of vitamin D did not affect concentrations of glucose pre- or postpartum. Concentrations of glucose sharply increased on the day of calving and then declined by 3 DIM and remained relatively stable thereafter (Figure 1G). Concentrations of insulin pre- and postpartum did not differ with treatment, but those of IGF1 prepartum were affected by the interaction $(P=$ 0.02 ) between DCAD and vitamin D because within cows fed positive DCAD, those receiving $\mathrm{PCH}$ tended $(P=0.07)$ to have greater IGF1 prepartum than those fed PCA. Concentrations of insulin and IGF1 decreased on the day of calving and then slowly increased $(P<$ 0.01 ) with DIM in all 4 treatments (Figure $1 \mathrm{H}$ and $1 \mathrm{I}$ ).

\section{Production Performance}

Intake of DM prepartum tended $(P=0.10)$ to be greater for cows fed positive than negative DCAD (positive $=11.9$ vs. negative $=11.0 \pm 0.4 \mathrm{~kg} / \mathrm{d}$ ), but no differences were observed for source of vitamin D (Table 3). Treatment did not influence DMI postpartum. Level of DCAD did not affect yields of milk or ECM, but cows fed CA produced more $(P<0.05)$ milk $(\mathrm{CH}=30.1$ vs. $\mathrm{CA}=34.8 \pm 1.5 \mathrm{~kg} / \mathrm{d})$ and $\mathrm{ECM}$ $(\mathrm{CH}=35.0$ vs. $\mathrm{CA}=39.9 \pm 1.7 \mathrm{~kg} / \mathrm{d})$ than cows fed $\mathrm{CH}$. Concentration of milk fat was greater $(P=0.01)$ for cows fed the negative compared with the positive DCAD (positive $=4.44$ vs. negative $=4.94 \pm 0.13 \%$ ) resulting in increased $(P=0.05)$ milk fat yield (positive $=1.41$ vs. negative $=1.63 \pm 0.08 \mathrm{~kg} / \mathrm{d}$ ). Cows fed CA tended $(P=0.10)$ to have greater milk fat yield than those fed $\mathrm{CH}(\mathrm{CH}=1.43$ vs. $\mathrm{CA}=1.62 \pm 0.08$ $\mathrm{kg} / \mathrm{d}$ ). Concentration and yield of true protein did not differ with treatments. Cows fed the diet with negative DCAD tended $(P=0.08)$ to be heavier postpartum than those fed the positive DCAD (608 vs. $571 \pm 14$ $\mathrm{kg}$ ), and those fed NCA had the greatest BCS postpartum. Parity responses were as expected, with parous cows having greater DMI $(P<0.05)$ being heavier $(P<$ $0.001)$ but having a lower $(P=0.006) \mathrm{BCS}$, and more milk, fat, and true protein than nulliparous cows. 


\section{Time Series Analysis}

Effect sizes and 95\% CI for cross-correlations between metabolites at lags 0 (on the same day) and $\pm 3,6$, and $9 \mathrm{~d}$ are presented in Tables 4 and 5 (for ease of reading, a combined table is available online: Supplemental Table S2; https://doi.org/10.3168/jds.2017-14033). These tests assess associations between metabolites over time within cows that are then pooled by treatment, whereas the mixed model analyses assess differences between treatment group responses. Nevertheless, it is unlikely that any particular lag in time series analysis will be optimal to assess all associations between metabolites, but a 3-d lag was assumed suitable for this type of analysis based on previous work (Lean et al., 1992a, 2014). The large number of comparisons studied and relatively limited sample size per group may produce some Type I and Type II statistical errors. Notwithstanding the potential for error, these data have provided many findings of interest and it should be noted that the effect size tests in Tables 4 and 5 are somewhat conservative because they are the pooled effects for 8 cows per treatment. For a group effect to be significant, there would have been similar and consistent correlations between the metabolites reported at the particular lag for each of the 8 cows.

A positive $\mathrm{ES}$ for 25 -hydroxyvitamin $\mathrm{D}_{3}$ and vitamin $\mathrm{D}_{3}$ was observed on the same day $(\mathrm{ES}=0.54)$ and 3 $\mathrm{d}$ later $(\mathrm{ES}=0.30)$ for only the PCH cows (Table 5$)$. The $\mathrm{PCH}$ cows were fed $\mathrm{CH}$ in doses larger than currently recommended by NRC (2001), and the positive ES on the same day, with a similar but nonsignificant ES for the NCH treatment, supports the hydroxylation of vitamin $\mathrm{D}_{3}$ to 25 -hydroxyvitamin $\mathrm{D}_{3}$ in the liver and elsewhere. Horst and Reinhardt (1983) discussed evidence for a product-based inhibition of 25-hydroxylase action in chickens and rats (Hughes et al., 1977) and provided evidence of lagged relationships of 10 to 25 $\mathrm{d}$ between increases in vitamin $\mathrm{D}_{3}$ and 25-hydroxyvitamin $\mathrm{D}_{3}$ concentrations in cattle. A negative ES was observed between these metabolites, again only in the $\mathrm{PCH}$ treatment $9 \mathrm{~d}$ later $(\mathrm{ES}=-0.38$; Table 4$)$, suggesting that 25-hydroxyvitamin $\mathrm{D}_{3}$ may exert feedback on vitamin $\mathrm{D}_{3}$, but not vice versa, at least in response to the $\mathrm{PCH}$ treatment or possibly differences in affinity to the vitamin $\mathrm{D}$ binding protein. The latter observation supports those findings and understandings of Horst and Reinhardt (1983). It is unclear why these findings were only significant in $\mathrm{PCH}$; however, cows fed $\mathrm{PCH}$ were the least successfully adapted in the transition period in this experiment, as they produced less milk (Martinez et al., 2018a) and had greater morbidity than NCA cows (Martinez et al., 2018b), suggesting a biological basis for the findings.
For several relationships including vitamin $D_{3}$ or 25-hydroxyvitamin $\mathrm{D}_{3}$, a significant effect of vitamin $\mathrm{D}$ treatment was observed, which might have reflected the substantial increase in supply of the respective vitamin D metabolite through the dietary interventions. Such instances include the associations between 25-hydroxyvitamin $\mathrm{D}_{3}$ and IGF1 3 d later $(\mathrm{ES}, \mathrm{PCH}$ $=0.51, \mathrm{PCA}=0.17, \mathrm{NCH}=0.36$, and $\mathrm{NCA}=0.32$; Table 4); between 25-hydroxyvitamin $\mathrm{D}_{3}$ and IGF1 9 d later $(\mathrm{ES}, \mathrm{PCH}=-0.41, \mathrm{PCA}=-0.14, \mathrm{NCH}=$ -0.42 , and $\mathrm{NCA}=-0.46$; Table 4 ); for vitamin $\mathrm{D}_{3}$ and IGF1 on the same day $(\mathrm{ES}, \mathrm{PCH}=0.56, \mathrm{PCA}$ $=0.21, \mathrm{NCH}=0.48$, and NCA $=0.22 ;$ Table 4$) ;$ and vitamin $\mathrm{D}_{3}$ and IGF1 3 d later $(\mathrm{ES}, \mathrm{PCH}=0.42, \mathrm{PCA}$ $=0.10, \mathrm{NCH}=0.41$, and $\mathrm{NCA}=-0.11$; Table 4). A physiological feedback mechanism is characterized by alternating positive and negative effects between 2 metabolic pathways and indicated by such alternating positive and negative ES between metabolites. Such physiological feedback mechanisms have been identified for energy metabolites and bone hormones in murine models (Lee et al., 2007; Clemens and Karsenty, 2011) and are evident here between 25-hydroxyvitamin $\mathrm{D}_{3}$ and IGF1 (Figure 2c) and vitamin $\mathrm{D}_{3}$ and IGF1 (Figure 3c). Differences were observed between 25-hydroxyvitamin $\mathrm{D}_{3}$ and vitamin $\mathrm{D}_{3}$ relationships with IGF1, with 25-hydroxyvitamin $\mathrm{D}_{3}$ having a positive association with IGF1 3 d later, followed 6 d later with a negative association; that is, at a lag of $9 \mathrm{~d}$. In contrast, there was an immediate positive association with vitamin D and IGF1 on the same day with evidence of negative feedback at lags of 6 and $9 \mathrm{~d}$. The actions of 25-hydroxyvitamin $\mathrm{D}_{3}$ and IGF1 are related in human studies of cancer (Tuohimaa, 2008) and diabetes (Hyppönen et al., 2008; Kamycheva et al., 2013), and 25-hydroxyvitamin $\mathrm{D}_{3}$, growth hormone, and IGF1 act synergistically to increase and integrate bone growth in humans (Giustina et al., 2008). Studies have shown that mice lacking the vitamin $\mathrm{D}$ receptor have $30 \%$ less IGF1 than mice with that receptor (Song et al., 2003). Interestingly, IGF1 upregulates $1 \alpha$-hydroxylase enzyme activity in the kidney, resulting in increased production of 1,25-dihydroxyvitamin $\mathrm{D}_{3}$ (Wei et al., 1997) and less production of 24,25-dihydroxyvitamin $\mathrm{D}_{3}$ (Tuohimaa, 2008). Further, 25-hydroxyvitamin $\mathrm{D}_{3}$ exerts positive feedback to increase the number of intracellular IGF1 receptors (Ogata et al., 2000). Vitamin D treatment increases both 25-hydroxyvitamin $\mathrm{D}_{3}$ and IGF1 concentrations in humans (Ameri et al., 2013).

Blood concentrations of IGF1 decreased in all treatments at the onset of lactation, as previously observed (Ronge et al., 1988; Vega et al., 1991; Moore et al., 2000). Before calving, cows fed the NCH diet had lower blood IGF1 concentrations than cows fed the other 
RODNEY ET AL.
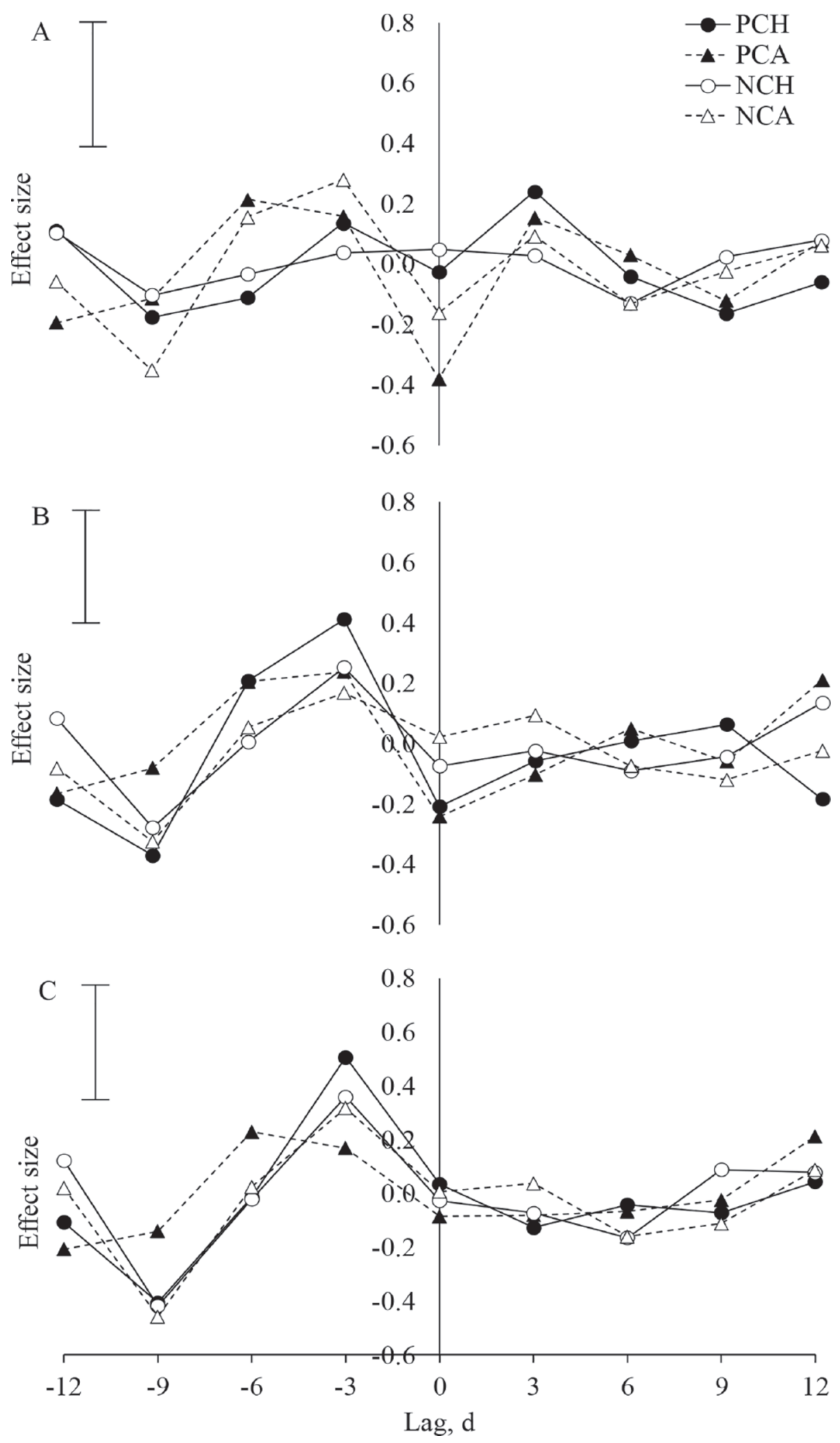

Figure 2. Effect size of the association of 25-hydroxyvitamin $\mathrm{D}_{3}$ with undercarboxylated osteocalcin (A), carboxylated osteocalcin (B), and IGF1 (C) according to treatment and 3-d lags. Prepartum, cows starting at $252 \mathrm{~d}$ of gestation were fed diets with either positive (P; +130 mEq/ $\mathrm{kg}$ ) or negative $(\mathrm{N} ;-130 \mathrm{mEq} / \mathrm{kg})$ DCAD and containing either $0.27 \mathrm{mg} / \mathrm{kg} \mathrm{DM}$ of cholecalciferol $(\mathrm{CH})$ or $0.27 \mathrm{mg} / \mathrm{kg} \mathrm{DM}$ of calcidiol $(\mathrm{CA})$. Error bars represent the pooled $95 \%$ CI for effect sizes. 

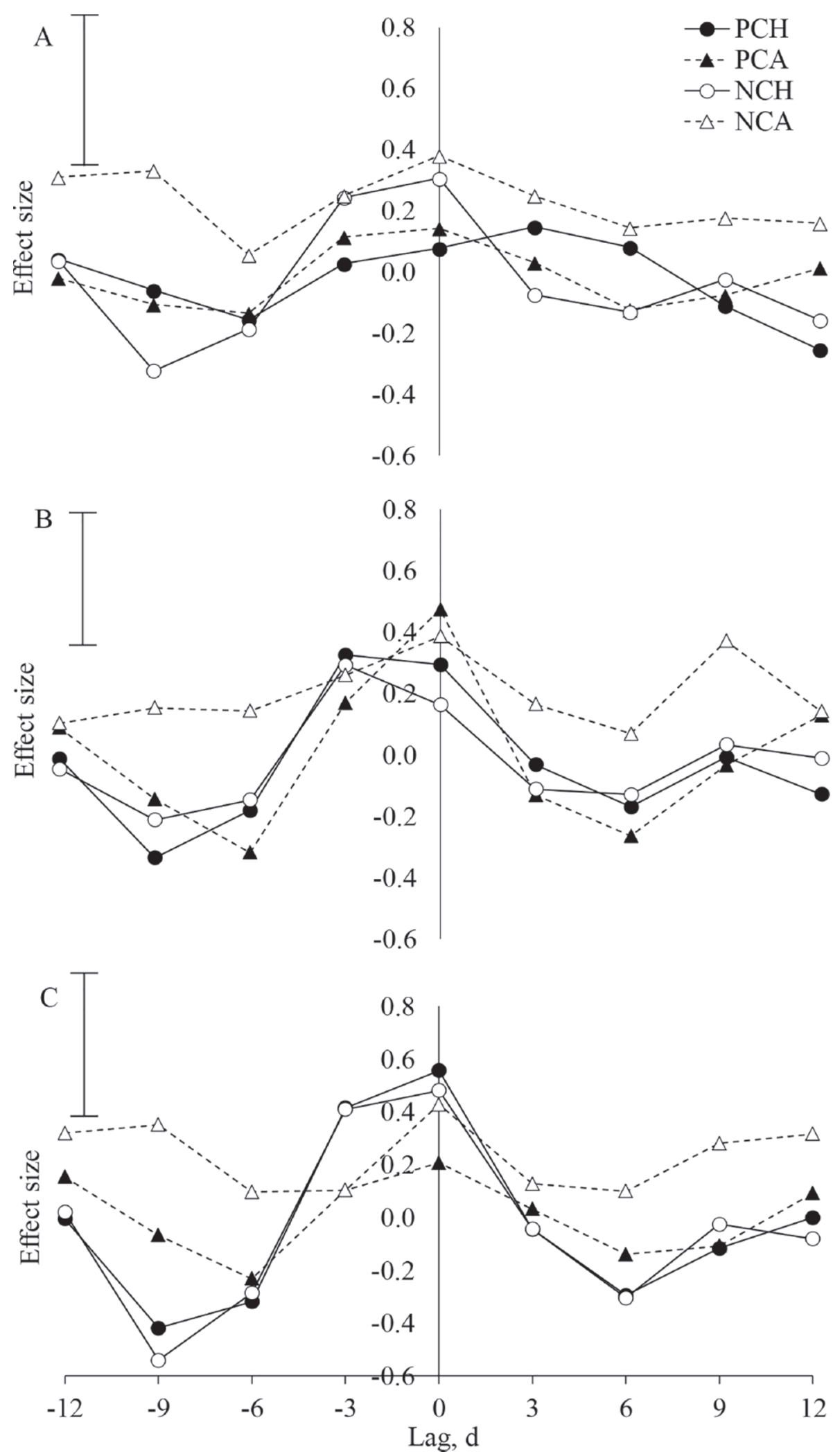

Figure 3. Effect size of the association of vitamin $\mathrm{D}_{3}$ with undercarboxylated osteocalcin $(\mathrm{A})$, carboxylated osteocalcin (B), and IGF1 (C) according to treatment and 3-d lags. Prepartum, cows starting at $252 \mathrm{~d}$ of gestation were fed diets with either positive $(\mathrm{P} ;+130 \mathrm{mEq} / \mathrm{kg}) \mathrm{or}$ negative $(\mathrm{N} ;-130 \mathrm{mEq} / \mathrm{kg})$ DCAD and containing either $0.27 \mathrm{mg} / \mathrm{kg}$ DM of cholecalciferol $(\mathrm{CH})$ or $0.27 \mathrm{mg} / \mathrm{kg} \mathrm{DM}$ of calcidiol (CA). Error bars represent the pooled $95 \%$ CI for effect sizes. 
treatments (61 vs. 73 to $81 \mathrm{ng} / \mathrm{mL}$, respectively). In contrast, Moore et al. (2000) did not identify a significant response of DCAD on blood IGF1 concentrations. Insulin-like growth factor 1 is important for cellular growth and differentiation, stimulates mammary cell proliferation (McGrath et al., 1991), and mediates the action of growth hormone on mammogenesis (Ruan et al., 1995; Plath-Gabler et al., 2001). Mammary cell apoptosis in both mice and cattle is inhibited by IGF1 (Neuenschwander et al., 1996; Accorsi et al., 2002). Further, and importantly, IGF1 stimulates mammary tissue DNA synthesis and milk production (Baumrucker and Stemberger, 1989).

The increased mineral demand associated with lactation may have been addressed, at least partly, in cows on all dietary treatments through increased bone breakdown and decreased bone remodeling, as identified by decreased $\mathrm{cOC}$ and $\mathrm{uOC}$ and increased CTX1 at the onset of lactation (Table 1; Rodney et al., 2018). Liesegang et al. (2000) reported a decrease in $\mathrm{OC}$ concentrations in early lactation that returned to prepartum concentrations by 30 DIM, a pattern similar to that observed in this study for cOC (Figure 1E). Liesegang et al. (2000) suggested that higher-producing cows mobilize more Ca from bone for groups of cows that differed in milk production by $1,600 \mathrm{~L}$ over a lactation. However, in the present experiment, blood concentrations of $\mathrm{OC}$, cOC, and CTX1 did not differ between treatments, despite the CA-supplemented cows producing $3.8 \mathrm{~L}$ more milk per day (Table 1). The results of this study are not directly comparable with those of Liesegang et al., (2000), who did not manipulate DCAD precalving nor provide supplemental vitamin D sources. Neither CA nor CH supplementation was associated with blood OC concentration when fed as a single 15-mg dose (Taylor et al., 2008) although calcitriol injection elevated plasma total $\mathrm{OC}$ and $\mathrm{uOC}$ concentrations in nonpregnant, nonlactating cows (Kim et al., 2011) and blood CTX1 concentrations in sheep (Wilkens et al., 2010). The metabolic acidosis resulting from a diet with negative DCAD may have been expected to influence bone metabolism indicators as a result of increased bone resorption and decreased osteogenesis, but only prepartum CTX1 concentrations tended to be increased in the cows receiving the $\mathrm{NCH}$ treatment prepartum $(P=0.068)$, a finding consistent with feeding acidogenic diets prepartum. Nevertheless, some experiments did not find effects of acidogenic diets on markers of bone metabolism in cattle (Moore et al., 2000; Liesegang et al., 2007). In the larger data set examined (Rodney et al., 2018), feeding acidogenic diets or supplementing $\mathrm{CH}$ increased concentrations of CTX1, but only in parous cows, whereas feeding acidogenic diets increased concentrations of cOC and total
OC only in nulliparous cows. In Rodney et al. (2018), the ratio of cOC to $\mathrm{CTX}-1$ (an index of bone turnover) was influenced by the interaction between DCAD and day relative to calving, and vitamin $\mathrm{D}$ and day relative to calving. Cows fed positive DCAD diets had a greater ratio on the day before calving than those fed the diets with negative DCAD, and cows fed CA had greater ratio on the day before calving than those fed $\mathrm{CH}$. Overall, evidence indicates that feeding an acidogenic diet can increase bone mobilization (Abu Damir et al., 1994) but the response is not consistent. There is also evidence that acidogenic diets enhance gastrointestinal absorption of Ca (Abu Damir et al., 1994; Wilkens et al., 2016). The inability to show changes in bone markers in the present experiment might suggest that the primary effect of the diets with negative DCAD was to increase absorption of $\mathrm{Ca}$ through the digestive tract (Wilkens et al., 2016), rather than mobilization from bone.

When examined over time, blood 25-hydroxyvitamin $\mathrm{D}_{3}$ and cOC concentrations were associated at negative lags (Table 4). The cross correlation of 25-hydroxyvitamin $\mathrm{D}_{3}$ and cOC $9 \mathrm{~d}$ later was negative $(\mathrm{ES}<-0.27)$ in all except cows fed PCA (ES $=-0.081$, not significant) and with a positive ES 3 d later (ES >0.16), although this was significant only for PCH cows $(\mathrm{ES}=0.412)$. These findings indicate that 25-hydroxyvitamin $\mathrm{D}_{3}$ exerts a negative feedback on cOC concentrations, an action consistent with a role of vitamin D in skeletal and energy metabolism. Lips (2006), in a review of 1,25-dihydroxyvitamin $\mathrm{D}_{3}$, noted its actions to upregulate or downregulate $\mathrm{OC}$ production in a process that can take place over days.

The ES for 25-hydroxyvitamin $\mathrm{D}_{3}$ and glucose on the same day were positive $(>0.16)$ but only significant for the $\mathrm{PCH}$ treatment $(\mathrm{ES}=0.80)$. Cows fed $\mathrm{PCH}$ also had significant ES of 25-hydroxyvitamin $\mathrm{D}_{3} 3 \mathrm{~d}$ before on glucose $(\mathrm{ES}=-0.21)$, and $6 \mathrm{~d}$ before on glucose $(\mathrm{ES}$ $=-0.25)$. The negative $\mathrm{ES}$ for 25-hydroxyvitamin $\mathrm{D}_{3}$ on glucose 6 d before was also significant in cows fed NCA (ES $=-0.28)$; all other treatments had nonsignificant ES that were larger than -0.14. Vitamin $\mathrm{D}_{3}$ also influenced glucose with significant ES on the same day and $3 \mathrm{~d}$ earlier for $\mathrm{PCH}$ and $\mathrm{NCH}$. These findings show a positive association between 25-hydroxyvitamin $\mathrm{D}_{3}$ or vitamin $\mathrm{D}_{3}$ with glucose on the same day, with evidence of negative feedback at lags of 3 and $6 \mathrm{~d}$. The results are consistent with the small positive or neutral effects on blood glucose concentrations in humans supplemented with vitamin D (George et al., 2012).

An association between OC and IGF1 has not previously been identified in the literature for cattle. Large positive ES were present between IGF1 and both uOC (ES $>0.79$ for all treatments) and cOC $(\mathrm{ES}>0.43$ for 
all but $\mathrm{PCH}$ ) on the same day (Figures $4 \mathrm{~A}$ and $\mathrm{B}$ ). Evidence of feedback was suggested for uOC, and particularly cOC, with IGF1 with negative feedback suggested 6 d later with $\mathrm{ES}<-0.21$ for IGF1 and cOC for all groups except NCA which was $\mathrm{ES}<-0.17$ for NCA.

Insulin-like growth factor 1 is essential for bone growth and maintenance of bone density (Ogata et al., 2000), increasing osteoblast proliferation and differentiation (Yeh et al., 1997; Li et al., 2009), and stimu- lating an increase in the concentration of $\mathrm{OC}$ in the osteoblasts (Li et al., 2009). There was little evidence of a treatment effect perturbing the associations between IGF1 and OC.

The conversion of $\mathrm{uOC}$ to cOC involves the vitamin $\mathrm{K}$-dependent carboxylation of glutamic residues to $\gamma$-carboxyglutamic acid, which has high affinity for bone. An increased concentration of uOC in mice, or selective inhibition of the Esp gene, which in turn inhibits
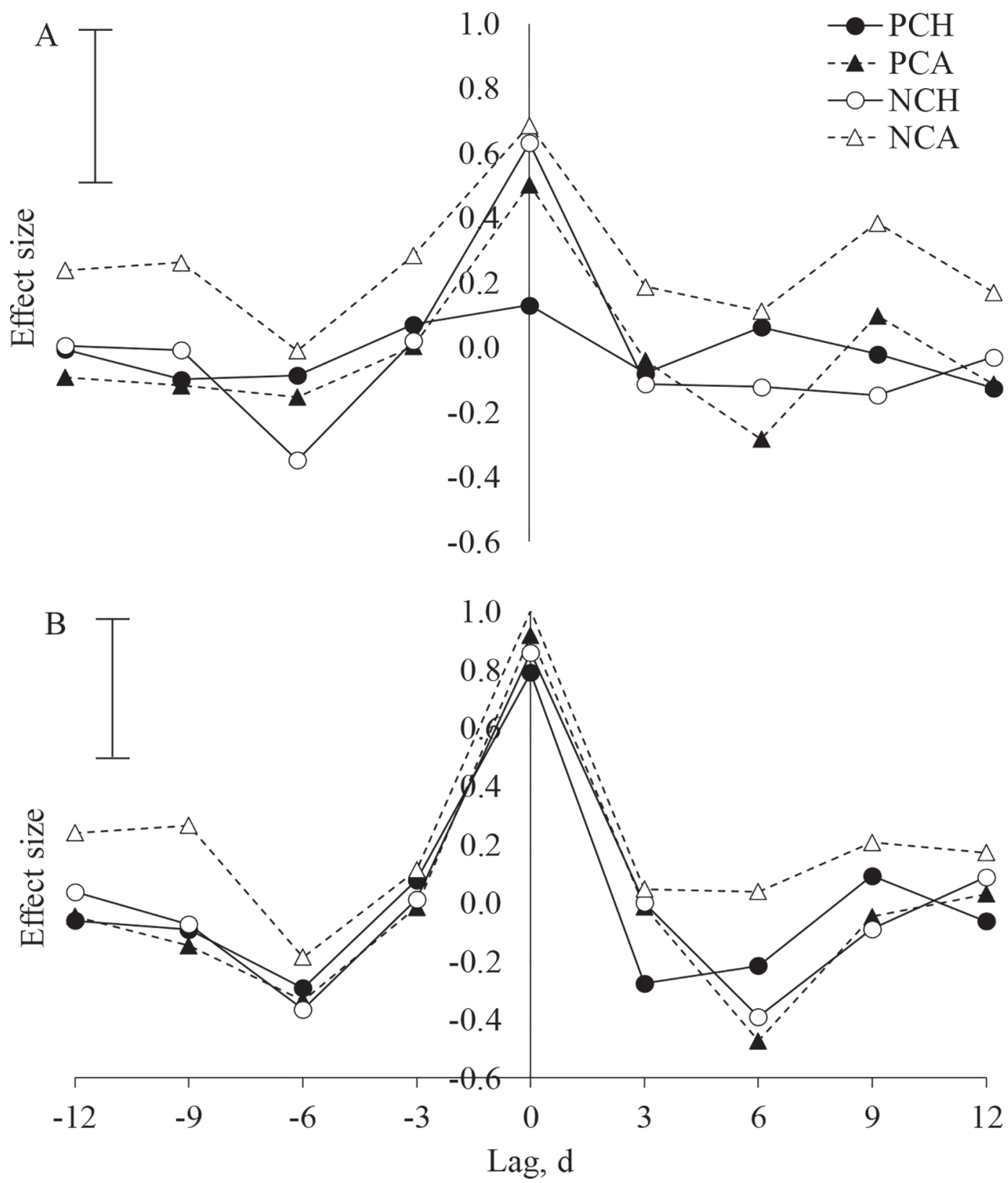

Figure 4. Effect size of the association of IGF1 with undercarboxylated osteocalcin (A) and carboxylated osteocalcin (B) according to treatment and 3-d lags. Prepartum, cows starting at $252 \mathrm{~d}$ of gestation were fed diets with either positive $(\mathrm{P} ;+130 \mathrm{mEq} / \mathrm{kg})$ or negative $(\mathrm{N} ;-130$ $\mathrm{mEq} / \mathrm{kg})$ DCAD and containing either $0.27 \mathrm{mg} / \mathrm{kg}$ DM of cholecalciferol $(\mathrm{CH})$ or $0.27 \mathrm{mg} / \mathrm{kg}$ DM of calcidiol (CA). Error bars represent the pooled $95 \%$ CI for effect sizes. 
carboxylation, increased insulin production and sensitivity (Lee et al., 2007). These observations suggested that $\mathrm{uOC}$ is the biologically active $\mathrm{OC}$ that influences energy metabolism. Similar patterns of significance (ES negative $6 \mathrm{~d}$ later, positive on the same day, negative 3 to $6 \mathrm{~d}$ before) were present between IGF1 and both forms of OC; however, these were greater for $\mathrm{cOC}$. This and the findings for 25-hydroxyvitamin $\mathrm{D}_{3}$ and cOC suggest that, at least in cattle, both $\mathrm{uOC}$ and cOC may have marked biological activity.

A negative ES existed between IGF1 and glucose $9 \mathrm{~d}$ before $(\mathrm{ES}<-0.26)$ in all treatments except for $\mathrm{NCH}$ $(\mathrm{ES}=-0.26$, not significant; Table 5$)$; however, significant positive ES between IGF1 and glucose $3 \mathrm{~d}$ before were present in all treatments (Table 5). This effect was stronger in cows fed diets with positive DCAD (ES = 0.58 and 0.46 for PCH and PCA vs. 0.22 and 0.28 for $\mathrm{NCH}$ and NCA, respectively). A positive ES was identified between IGF1 and insulin on the same day in PCA and $\mathrm{NCH}$ treatments (ES $=0.29$ and 0.35 , respectively; Table 5). Feeding positive DCAD diets resulted in increased glucose concentrations prepartum, possibly due to increased intake or decreased disposal of glucose or increased insulin resistance. Associations between IGF1 and glucose are logical and reflect the stimulatory effect of glucose on production mediated through IGF1. A negative feedback for this relationship is consistent with the tight homeostatic control of blood glucose.

Insulin secretion and sensitivity are stimulated by OC (Lee et al., 2007; Wolf, 2008; Clemens and Karsenty, 2011), but this effect was not identified in this study. However, the association between uOC and $\mathrm{cOC}$ and glucose concentrations identified in mice showing greater uptake of glucose in peripheral tissues and increased insulin sensitivity (Lee et al., 2007) was supported. There was a negative ES for glucose with both $\mathrm{uOC}$ and cOC $9 \mathrm{~d}$ before in cows fed CA (ES $<-0.34$ ), a positive ES for $\mathrm{uOC}$ and glucose $3 \mathrm{~d}$ before in cows fed CA $(\mathrm{ES}>0.25)$, and a positive ES for $\mathrm{cOC}$ and glucose $3 \mathrm{~d}$ before in cows fed the diets with positive DCAD (ES >0.32). These associations are similar to those for IGF1 and glucose, supporting associations between glucose, IGF1, and OC as part of the homeorhetic control of metabolism. Further, the negative association of CTX1 with glucose concentrations $3 \mathrm{~d}$ before $(\mathrm{ES}<-0.27)$ in all but $\mathrm{NCA}(\mathrm{ES}=$ -0.24 , not significant; Table 5) highlights the anabolic signals associated with increased blood glucose concentrations. Similarly, there was evidence that CTX1 and insulin were negatively associated on the same day in the NCH and PCA treatments, and positive associations were present for CTX1 3 or $6 \mathrm{~d}$ before with insulin in the NCH and PCA treatments, respectively (Table 4). These findings are consistent with strong positive associations found between CTX1 and OC and CTX1 and insulin in pregnant women (Winhofer et al., 2012). Further, concentrations of CTX1 are greater in women with gestational diabetes (Winhofer et al., 2012), a condition characterized by insulin resistance, and with a similar insulin resistance in late gestation and early lactation (McNamara, 1991; Bell, 1995). Clemens and Karsenty (2011) discussed the evidence that insulin is involved in the regulation of bone resorption through a forward regulating loop that includes OC, which decarboxylates to $\mathrm{uOC}$ under acidic conditions and increases insulin sensitivity of peripheral tissues and increases insulin production from pancreatic $\beta$-cells.

Vitamin D was associated with bone mobilization, as a positive ES was identified between 25-hydroxyvitamin $\mathrm{D}_{3}$ and CTX1 9 d later in PCH and NCA treatments ( $\mathrm{ES}=0.22$ and 0.39 , respectively; Table 4 ), and a negative effect of vitamin $\mathrm{D}_{3}$ on CTX1 3 d later in both groups of cows fed $\mathrm{CH}(\mathrm{ES}<-0.24$; Table 4$)$. A negative ES was identified between IGF1 and CTX1 on the same day in all but $\mathrm{NCH}(\mathrm{ES}<-0.22$ and $=-0.17$ for $\mathrm{NCH}$; Table 4). This effect was coupled with a positive association between IGF1 and both $\mathrm{uOC}$ and cOC on the same day, indicating that IGF1 may preserve bone mass, a finding consistent with Ogata et al. (2000) and the very substantial role of growth hormone and IGF1 in bone development (Giustina et al., 2008).

A negative association was identified for CTX1 with glucose $3 \mathrm{~d}$ before in all treatments $(\mathrm{ES}<-0.27)$, except for NCA (ES $=-0.24)$, and for CTX1 and insulin on the same day in $\mathrm{NCH}$ and PCA treatments $(\mathrm{ES}=-0.24$ and -0.47 , respectively). The feedback mechanism that exists between glucose and insulin is well established but not observed here, as ES between the 2 were generally close to zero. The timing of this feedback between glucose and insulin might have differed from the 3-d lags examined. It is also possible that the constant gluconeogenic state of cows and lack of insulin sensitivity in the immediate periparturient period (Baldwin and Smith, 1979) limited expression of this effect. Notwithstanding the latter suggestion, in the larger experiment (Martinez et al., 2018a), cows fed the diet with positive DCAD had greater prepartum concentrations of glucose, insulin, and IGF1 compared with cows fed the diet with negative DCAD, and the increases in insulin and IGF1 with the positive compared with the negative DCAD diet were more exacerbated in cows fed CA. These findings suggest the possibility that some degree of insulin sensitivity may be restored in cows fed a negative DCAD diet.

Nulliparous cows had increased blood concentrations of bone and energy-related metabolites ( $\mathrm{uOC}$, cOC, CTX1, IGF1, glucose, and insulin) compared with parous cows, a finding consistent with Sato et al. (2011) 
and Taylor et al. (2008), who found that younger cows had increased serum OC concentrations. This finding might reflect a need for nulliparous cows to accrete and remodel bone to a greater extent than parous cows or reflect lesser loss of glucose and minerals to milk production. Prepartum, plasma CTX1 concentrations were greater in nulliparous than parous cows, although concentrations did not differ between parity groups postpartum. Moore et al. (2000) found higher plasma concentrations of hydroxyapatite in nulliparous than parous cows. Concentrations of IGF1 also were greater in nulliparous than parous cows before and after calving, a finding which is consistent with Moore et al. (2000).

Relationships were not identified between adiponectin and OC (data not presented), despite the stimulatory action of $\mathrm{OC}$ on adiponectin (Tschritter et al., 2003). Adiponectin is also associated with increased proliferation and differentiation of osteoblasts (Berner et al., 2004), resulting in increased bone deposition (Kanazawa et al., 2007). Moreover, we did not detect any clear association between adiponectin and indicators of energy metabolism. These associations may have been expected because adiponectin increases glucose uptake by skeletal muscle and may suppress hepatic gluconeogenesis (Yamauchi et al., 2002), and a positive correlation between plasma insulin and adiponectin has been observed (Singh et al., 2014).

\section{CONCLUSIONS}

This study provides evidence that the relationships between bone and energy metabolism observed in humans and mice exist in cattle. We found evidence that vitamin $\mathrm{D}_{3}$ and 25-hydroxyvitamin $\mathrm{D}_{3}$ were part of the integrated cross-talk between bone and energy metabolism. In particular, the pattern of strong positive ES between vitamin $\mathrm{D}_{3}$ and IGF1, and between $\mathrm{OC}$ and IGF1 on the same day and positive and negative ES at other lags provides evidence for a feedback mechanism between these compounds. The relationship between OC and IGF1 had not previously been identified in cattle. As these mechanisms were observed with both $\mathrm{uOC}$ and $\mathrm{cOC}$, it suggested, at least in dairy cattle, that both forms of $\mathrm{OC}$ might have biological activity. The linkage between $\mathrm{OC}$ and insulin identified in murine studies was not observed herein, although associations between OC and glucose were detected and similar to those of IGF1 and glucose, supporting associations between these 2 hormones and energy metabolism. The associations between hormones linked to bone and energy metabolism may be an important part of the physiological process by which prepartum dietary interventions integrate different aspects of metabolism and have positive and long-lasting effects on production and health in dairy cows. Observations made in this study reinforce the importance of feeding diets with negative DCAD before calving and support the need to enhance vitamin $\mathrm{D}$ function in periparturient cows.

\section{ACKNOWLEDGMENTS}

The authors thank Rafael S. Bisinotto, André L. G. Dias, José Freitas, Gabriel C. Gomes, Leandro F. Greco, Camilo Lopera, Kathryn Merriman, Kaitlin M. O'Connor, Adele Pietras, Guilherme C.S. Pontes, Eduardo S. Ribeiro, Rosiane Sales, Ricarda M. Santos, Sergei Sennikov, Johnathan Smith, Marcos Zenobi, and Matthew Wadford from the University of Florida (Gainesville) for their help with the conduct of the experiment. Financial support was provided by Arm \& Hammer Animal Nutrition (Princeton, NJ), DSM Nutritional Products (Kaiseraugst, Switzerland), Scibus (Camden, SW, Australia) and Dairy Australia (Southbank, VIC, Australia).

\section{REFERENCES}

Abu Damir, H., M. Phillippo, B. H. Thorp, J. S. Milne, L. Dick, and I. M. Nevison. 1994. Effects of dietary acidity on calcium balance and mobilization, bone morphology and 1,25 dihydroxyvitamin D in prepartal dairy cows. Res. Vet. Sci. 56:310-318.

Accorsi, P. A., B. Pacioni, C. Pezzi, M. Forni, D. Flint, and E. Seren. 2002. Role of prolactin, growth hormone and insulin-like growth factor 1 in mammary gland involution in the dairy cow. J. Dairy Sci. 85:507-513.

Ameri, P., A. Giusti, M. Boschetti, G. Murialdo, F. Minuto, and D. Ferone. 2013. Interactions between vitamin D and IGF-I: From physiology to clinical practice. Clin. Endocrinol. (Oxf.) 79:457-463.

Baldwin, R. L., and N. E. Smith. 1979. Regulation of energy metabolism in ruminants. Pages $1-27$ in Advances in Nutritional Research. H. H. Draper, Plenum Press, New York, NY.

Bauman, D. E., and W. B. Currie. 1980. Partitioning of nutrients during pregnancy and lactation: A review of mechanisms involving homeostasis and homeorhesis. J. Dairy Sci. 63:1514-1529.

Baumrucker, C. R., and B. Stemberger. 1989. Insulin and insulin-like growth factor-I stimulate DNA synthesis in bovine mammary tissue in vitro. J. Anim. Sci. 67:3503-3514.

Bell, A. W. 1995. Regulation of organic nutrient metabolism during transition from late pregnancy to early lactation. J. Anim. Sci. 73:2804-2819.

Berner, H. S., S. P. Lyngstadaas, A. Spahr, M. Monjo, L. Thommesen, C. A. Drevon, U. Syversen, and J. E. Reseland. 2004. Adiponectin and its receptors are expressed in bone-forming cells. Bone 35:842-849.

Bikle, D. D., E. Gee, B. Halloran, M. A. Kowalski, E. Ryzen, and J. G. Haddad. 1986. Assessment of the free fraction of 25-hydroxyvitamin D in serum and its regulation by albumin and the vitamin D-binding protein. J. Clin. Endocrinol. Metab. 63:954-959.

Box, G. E. P., and D. R. Cox. 1964. An analysis of transformations. J. R. Stat. Soc. B 26:211-252.

Clemens, T. L., and G. Karsenty. 2011. The osteoblast: An insulin target cell controlling glucose homeostasis. J. Bone Miner. Res. 26:677-680.

Cohen, J. 1988. Statistical power analysis for the behavioral sciences. 2nd ed. Lawrence Earlbaum Associates, Hillsdale, NJ.

DeGaris, P. J., I. Lean, A. Rabiee, and M. Stevenson. 2010. Effects of increasing days of exposure to prepartum diets on the concen- 
tration of certain blood metabolites in dairy cows. Aust. Vet. J. $88: 137-145$

DerSimonian, R., and N. Laird. 1986. Meta-analysis in clinical trials. Control. Clin. Trials 7:177-188.

George, P. S., E. Pearson, and M. Witham. 2012. Effect of vitamin D supplementation on glycaemic control and insulin resistance: A systematic review and meta-analysis. Diabet. Med. 29:e142-150.

Giustina, A., G. Mazziotti, and E. Canalis. 2008. Growth hormone, insulin-like growth factors, and the skeleton. Endocr. Rev. 29:535559 .

Gochman, N., and J. M. Schmitz. 1972. Application of a new peroxide indicator reaction to the specific, automated determination of glucose with glucose oxidase. Clin. Chem. 18:943-950.

Goff, J. P., and R. L. Horst. 1997. Effects of the addition of potassium or sodium, but not calcium, to prepartum rations on milk fever in dairy cows. J. Dairy Sci. 80:176-186.

Goff, J. P., R. L. Horst, F. J. Mueller, J. K. Miller, G. A. Kiess, and H. H. Dowlen. 1991. Addition of chloride to a prepartal diet high in cations increases 1,25-dihydroxyvitamin D response to hypocalcemia preventing milk fever. J. Dairy Sci. 74:3863-3871.

Goff, J. P., A. Liesegang, and R. Horst. 2014. Diet-induced pseudohypoparathyroidism: A hypocalcemia and milk fever risk factor. J. Dairy Sci. 97:1520-1528.

Haddad, J. G., L. Y. Matsuoka, B. W. Hollis, Y. Z. Hu, and J. Wortsman. 1993. Human plasma transport of vitamin d after its endogenous synthesis. J. Clin. Invest. 91:2552-2555.

Hedges, L. V., and J. L. Vevea. 1998. Fixed-and random-effects models in meta-analysis. Psychol. Methods 3:486-504.

Heuer, C., Y. Schukken, and P. Dobbelaar. 1999. Postpartum body condition score and results from the first test day milk as predictors of disease, fertility, yield, and culling in commercial dairy herds. J. Dairy Sci. 82:295-304.

Horst, R. L., J. Goff, and T. Reinhardt. 1994. Calcium and vitamin d metabolism in the dairy cow. J. Dairy Sci. 77:1936-1951.

Horst, R. L., and T. Reinhardt. 1983. Vitamin D metabolism in ruminants and its relevance to the periparturient cow. J. Dairy Sci. 66:661-678.

Hughes, M. R., D. J. Baylink, W. A. Gonnerman, S. U. Toverud, W. K. Ramp, and M. R. Haussler. 1977. Influence of dietary vitamin $\mathrm{D}_{3}$ on the circulating concentration of its active metabolites in the chick and rat. Endocrinology 100:799-806.

Hymøller, L., S. K. Jensen, P. Kass, and J. Jakobsen. 2017. Physiological limit of the daily endogenous cholecalciferol synthesis from UV light in cattle. J. Anim. Physiol. Anim. Nutr. (Berl.) 101:215-221.

Hyppönen, E., B. J. Boucher, D. J. Berry, and C. Power. 2008. 25-hydroxyvitamin D, IGF-1, and metabolic syndrome at 45 years of age. Diabetes 57:298-305.

Jørgensen, E., and A. R. Pedersen. 1998. How to obtain those nasty standard errors from transformed data - and why they should not be used. Biometry Research Unit - Internal report 7. Danish Institute of Agricultural Sciences, Tjele, Denmark.

Kamycheva, E., V. Berg, and R. Jorde. 2013. Insulin-like growth factor I, growth hormone, and insulin sensitivity: The effects of a oneyear cholecalciferol supplementation in middle-aged overweight and obese subjects. Endocrine 43:412-418.

Kanazawa, I., T. Yamaguchi, S. Yano, M. Yamauchi, M. Yamamoto, and T. Sugimoto. 2007. Adiponectin and AMP kinase activator stimulate proliferation, differentiation, and mineralization of osteoblastic MC3T3-E1 cells. BMC Cell Biol. 8:51-62.

Kim, D., Y. Kawakami, N. Yamagishi, I. Abe, K. Furuhama, B. Devkota, N. Okura, S. Sato, and S. Ohashi. 2011. Response of plasma bone markers to a single intramuscular administration of calcitriol in dairy cows. Res. Vet. Sci. 90:124-126.

Lean, I. J., P. J. DeGaris, P. Celi, D. M. McNeill, R. M. Rodney, and D. R. Fraser. 2014. Influencing the future: Interactions of skeleton, energy, protein and calcium during late gestation and early lactation. Anim. Prod. Sci. 54:1177-1189.

Lean, I. J., T. Farver, H. Troutt, M. Bruss, J. Galland, R. Baldwin, C. Holmberg, and L. Weaver. 1992a. Time series cross-correlation analysis of postparturient relationships among serum metabolites and yield variables in Holstein cows. J. Dairy Sci. 75:1891-1900.
Lee, N. K., H. Sowa, E. Hinoi, M. Ferron, J. D. Ahn, C. Confavreux, R. Dacquin, P. J. Mee, M. D. McKee, D. Y. Jung, Z. Zhang, J. K. Kim, F. Mauvais-Jarvis, P. Ducy, and G. Karsenty. 2007. Endocrine regulation of energy metabolism by the skeleton. Cell 130:456-469.

Li, S.-H., D.-Z. Guo, B. Li, H.-B. Yin, J.-K. Li, J.-M. Xiang, and G.-Z. Deng. 2009. The stimulatory effect of insulin-like growth factor-1 on the proliferation, differentiation, and mineralisation of osteoblastic cells from Holstein cattle. Vet. J. 179:430-436.

Liesegang, A., C. Chiappi, J. Risteli, J. Kessler, and H. D. Hess. 2007. Influence of different calcium contents in diets supplemented with anionic salts on bone metabolism in periparturient dairy cows. J. Anim. Physiol. Anim. Nutr. (Berl.) 91:120-129.

Liesegang, A., R. Eicher, M.-L. Sassi, J. Risteli, M. Kraenzlin, J.-L. Riond, and M. Wanner. 2000. Biochemical markers of bone formation and resorption around parturition and during lactation in dairy cows with high and low standard milk yields. J. Dairy Sci. $83: 1773-1781$.

Lips, P. 2006. Vitamin D physiology. Prog. Biophys. Mol. Biol. 92:4-8. Martinez, N., R. M. Rodney, E. Block, L. L. Hernandez, C. D. Nelson, I. J. Lean, and J. E. P. Santos. 2018a. Effects of prepartum dietary cation-anion difference and source of vitamin D on dairy cows: lactation performance and energy metabolism. J. Dairy Sci. 101:2544-2562.

Martinez, N., R. M. Rodney, E. Block, L. L. Hernandez, C. D. Nelson, I. J. Lean, and J. E. P. Santos. 2018b. Effects of prepartum dietary cation-anion difference and source of vitamin D on dairy cows: health and reproductive responses. J. Dairy Sci. 101:2563-2578.

Martinez, N., L. Sinedino, R. Bisinotto, E. Ribeiro, G. Gomes, F. Lima, L. Greco, C. Risco, K. Galvão, and D. Taylor-Rodriguez. 2014. Effect of induced subclinical hypocalcemia on physiological responses and neutrophil function in dairy cows. J. Dairy Sci. 97:874-887.

McGrath, M. F., R. J. Collier, D. R. Clemmons, W. Busby, C. Sweeny, and G. Krivi. 1991. The direct in vitro effect of insulin-like growth factors (IGFs) on normal bovine mammary cell proliferation and production of IGF binding proteins. Endocrinology 129:671-678.

McNamara, J. P. 1991. Regulation of adipose tissue metabolism in support of lactation. J. Dairy Sci. 74:706-719.

Moore, S. J., M. VandeHaar, B. Sharma, T. Pilbeam, D. Beede, H. Bucholtz, J. Liesman, R. Horst, and J. Goff. 2000. Effects of altering dietary cation-anion difference on calcium and energy metabolism in peripartum cows. J. Dairy Sci. 83:2095-2104.

NRC. 2001. Nutrient Requirements of Dairy Cattle. 7th ed. National Academies Press, Washington, DC.

Neuenschwander, S., A. Schwartz, T. L. Wood, C. T. Roberts Jr., L. Hennighausen, and D. LeRoith. 1996. Involution of the lactating mammary gland is inhibited by the igf system in a transgenic mouse model. J. Clin. Invest. 97:2225-2232.

Oetzel, G. R., M. J. Fettman, D. W. Hamar, and J. D. Olson. 1991 Screening of anionic salts for palatability, effects on acid-base status, and urinary calcium excretion in dairy cows. J. Dairy Sci. 74:965-971.

Ogata, N., D. Chikazu, N. Kubota, Y. Terauchi, K. Tobe, Y. Azuma, T. Ohta, T. Kadowaki, K. Nakamura, and H. Kawaguchi. 2000. Insulin receptor substrate-1 in osteoblast is indispensable for maintaining bone turnover. J. Clin. Invest. 105:935-943.

Palmer, T. M., and J. A. C. Sterne. J. 2009. Meta-analysis in Stata: An updated collection from the Stata Journal. 2nd Ed., Stata Press Publication, College Station, TX.

Phillippo, M., G. W. Reid, and I. M. Nevison. 1994. Parturient hypocalcaemia in dairy cows: effects of dietary acidity on plasma minerals and calciotrophic hormones. Res. Vet. Sci. 56:303-309.

Plath-Gabler, A., C. Gabler, F. Sinowatz, B. Berisha, and D. Schams. 2001. The expression of the IGF family and GH receptor in the bovine mammary gland. J. Endocrinol. 168:39-48.

Rodney, R. M., N. Martinez, E. Block, L. L. Hernandez, P. Celi, C D. Nelson, J. E. P. Santos, and I. J. Lean. 2018. Effects of prepartum dietary cation-anion difference and source of vitamin D on dairy cows: Vitamin D, mineral and bone metabolism. J. Dairy Sci. 101:2519-2543. 
Ronge, H., J. Blum, C. Clement, F. Jans, H. Leuenberger, and H. Binder. 1988. Somatomedin c in dairy cows related to energy and protein supply and to milk production. Anim. Prod. 47:165-183.

Ruan, W., V. Catanese, R. Wieczorek, M. Feldman, and D. L. Kleinberg. 1995. Estradiol enhances the stimulatory effect of insulin-like growth factor-I (IGF-I) on mammary development and growth hormone-induced IGF-I messenger ribonucleic acid. Endocrinology 136:1296-1302.

Sato, R., K. Onda, H. Ochiai, T. Iriki, Y. Yamazaki, and Y. Wada 2011. Serum osteocalcin in dairy cows: Age-related changes and periparturient variation. Res. Vet. Sci. 91:196-198.

Shumway, R. H. 1988. Applied Statistical Time Series Analysis. Prentice Hall Series in Statistics, Prentice-Hall, Englewood Cliffs, NJ.

Sidler-Lauff, K., A. Boos, M. Kraenzlin, and A. Liesegang. 2010. Influence of different calcium supplies and a single vitamin D injection on vitamin $\mathrm{D}$ receptor and calbindin D9k immunoreactivities in the gastrointestinal tract of goat kids. J. Anim. Sci. 88:3598-3610.

Singh, S. P., S. Häussler, J. Heinz, S. Akter, B. Saremi, U. Müller, J. Rehage, S. Dänicke, M. Mielenz, and H. Sauerwein. 2014. Lactation driven dynamics of adiponectin supply from different fat depots to circulation in cows. Domest. Anim. Endocrinol. 47:35-46.

Song, Y.. S. Kato, and J. C. Fleet. 2003. Vitamin D receptor (VDR) knockout mice reveal VDR-independent regulation of intestinal calcium absorption and $\mathrm{ECaC} 2$ and calbindin D9k mRNA. J. Nutr. 133:374-380.

Tanaka, Y., and H. DeLuca. 1971. Bone mineral mobilization activity of 1, 25-dihydroxycholecalciferol, a metabolite of vitamin D. Arch. Biochem. Biophys. 146:574-578.

Taylor, M. S., K. Knowlton, M. McGilliard, W. Seymour, and J. Herbein. 2008. Blood mineral, hormone, and osteocalcin responses of multiparous Jersey cows to an oral dose of 25-hydroxyvitamin $\mathrm{D}_{3}$ or vitamin $\mathrm{D}_{3}$ before parturition. J. Dairy Sci. 91:2408-2416.

Terpening, C. M., C. A. Haussler, P. W. Jurutka, M. A. Galligan, B. S. Komm, and M. R. Haussler. 1991. The vitamin D-responsive element in the rat bone Gla protein gene is an imperfect direct repeat that cooperates with other cis-elements in 1,25-dihydroxyvitamin $\mathrm{D}_{3}$-mediated transcriptional activation. Mol. Endocrinol. $5: 373-385$.

Tschritter, O., A. Fritsche, C. Thamer, M. Haap, F. Shirkavand, S. Rahe, H. Staiger, E. Maerker, H. Häring, and M. Stumvoll. 2003. Plasma adiponectin concentrations predict insulin sensitivity of both glucose and lipid metabolism. Diabetes 52:239-243.

Tuohimaa, P. 2008. Vitamin D, aging, and cancer. Nutr. Rev. 66:S147S152.

Uchida, M., K. Ozono, and J. W. Pike. 1994. Activation of the human osteocalcin gene by $24 \mathrm{R}, 25$-dihydroxyvitamin $\mathrm{D}_{3}$ occurs through the vitamin $\mathrm{D}$ receptor and the vitamin D-responsive element. J. Bone Miner. Res. 9:1981-1987. van Mosel, M., and S. C. Corlett. 1990. Assessment of bone turnover in the dry period of dairy cows by measurement of plasma bone Glaprotein, total plasma alkaline phosphatase activity and urinary hydroxyproline. Exp. Physiol. 75:827-837.

Vega, J. R., C. Gibson, T. Skaar, D. Hadsell, and C. Baumrucker. 1991. Insulin-like growth factor (IGF)-I and-II and IGF binding proteins in serum and mammary secretions during the dry period and early lactation in dairy cows. J. Anim. Sci. 69:2538-2547.

Wei, J., and G. Karsenty. 2015. An overview of the metabolic functions of osteocalcin. Rev. Endocr. Metab. Disord. 16:93-98.

Wei, S., H. Tanaka, T. Kubo, T. Ono, S. Kanzaki, and Y. Seino. 1997. Growth hormone increases serum 1, 25-dihydroxyvitamin D levels and decreases 24, 25-dihydroxyvitamin D levels in children with growth hormone deficiency. Eur. J. Endocrinol. 136:45-51.

Weiss, W. P., E. Azem, W. Steinberg, and T. Reinhardt. 2015. Effect of feeding 25-hydroxyvitamin $\mathrm{D}_{3}$ with a negative cation-anion difference diet on calcium and vitamin $\mathrm{D}$ status of periparturient cows and their calves. J. Dairy Sci. 98:5588-5600.

Wilkens, M. R., N. Mrochen, G. Breves, and B. Schröder. 2010. Effects of 1,25-dihydroxyvitamin $\mathrm{D}_{3}$ on calcium and phosphorus homeostasis in sheep fed diets either adequate or restricted in calcium content. Domest. Anim. Endocrinol. 38:190-199.

Wilkens, M. R., I. Oberheide, B. Schröder, E. Azem, W. Steinberg, and G. Breves. 2012. Influence of the combination of 25-hydroxyvitamin $\mathrm{D}_{3}$ and a diet negative in cation-anion difference on peripartal calcium homeostasis of dairy cows. J. Dairy Sci. 95:151-164.

Wilkens, M. R., C. Praechter, G. Breves, and B. Schröder. 2016. Stimulating effects of a diet negative in dietary cation-anion difference on calcium absorption from the rumen in sheep. J. Anim. Physiol. Anim. Nutr. (Berl.) 100:156-166.

Winhofer, Y., F. W. Kiefer, A. Handisurya, A. Tura, K. Klein, B. Schneider, R. Marculescu, O. F. Wagner, G. Pacini, and A. Luger. 2012. CTX (crosslaps) rather than osteopontin is associated with disturbed glucose metabolism in gestational diabetes. PLoS One 7:e40947.

Wolf, G. 2008. Energy regulation by the skeleton. Nutr. Rev. 66:229 233.

Yamauchi, T., J. Kamon, Y. a. Minokoshi, Y. Ito, H. Waki, S. Uchida, S. Yamashita, M. Noda, S. Kita, and K. Ueki. 2002. Adiponectin stimulates glucose utilization and fatty-acid oxidation by activating amp-activated protein kinase. Nat. Med. 8:1288-1295.

Yeh, L.-C. C., M. L. Adamo, M. S. Olson, and J. C. Lee. 1997. Osteogenic protein-1 and insulin-like growth factor I synergistically stimulate rat osteoblastic cell differentiation and proliferation 1. Endocrinology 138:4181-4190. 